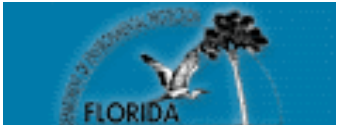

Florida Department of Environmental Protection

Southeast Regional Partnership

for Planning and Sustainability (SERPPAS)

Southeastern Regional Partnership for Planning and Sustainability

\title{
Mapping of Florida's Coastal and Marine Resources: Setting Priorities Workshop
}

Whitepaper

By Lisa Robbins, Steven Wolfe, and Ellen Raabe

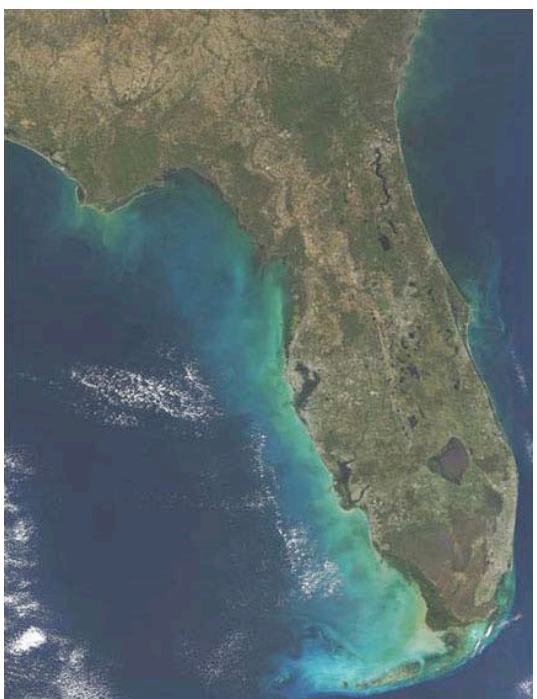

Open-File Report 2008-1157

2008

U.S. Department of the Interior

U.S. Geological Survey 


\section{U.S. Department of the Interior DIRK KEMPTHORNE, Secretary}

\section{U.S. Geological Survey \\ Mark D. Myers, Director}

U.S. Geological Survey, Reston, Virginia 2008

Revised and reprinted: 2008

For product and ordering information:

World Wide Web: http://www.usgs.gov/pubprod

Telephone: 1-888-ASK-USGS

For more information on the USGS - the Federal source for science about the Earth,

its natural and living resources, natural hazards, and the environment:

World Wide Web: http://www.usgs.gov

Telephone: 1-888-ASK-USGS

Suggested citation:

Robbins, Lisa, Wolfe, Steven, and Raabe, Ellen, 2008, Mapping of Florida's Coastal and Marine Resources: Setting Priorities Workshop: U.S. Geological Survey Open-File Report 2008-1157, 36 pages; St. Petersburg, FL.

Any use of trade, product, or firm names is for descriptive purposes only and does not imply endorsement by the U.S. Government.

Although this report is in the public domain, permission must be secured from the individual copyright owners to reproduce any copyrighted material contained within this report. 


\section{Contents}

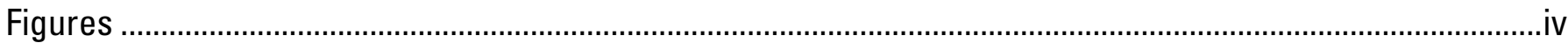

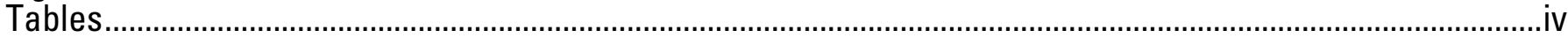

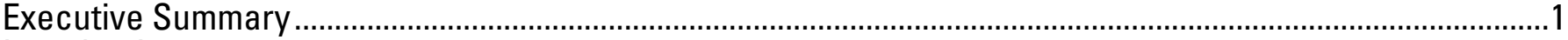

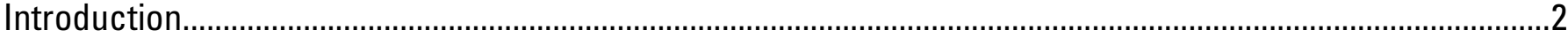

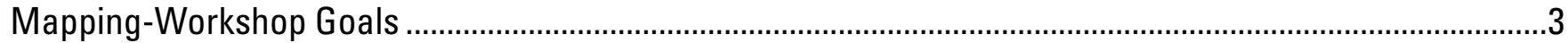

Mapping Technology, Scales, and Resolution ..........................................................................................

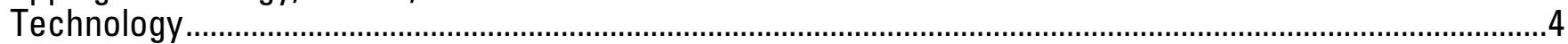

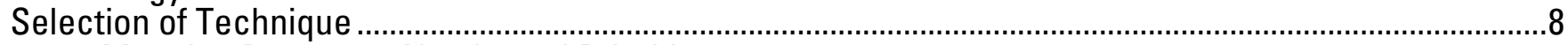

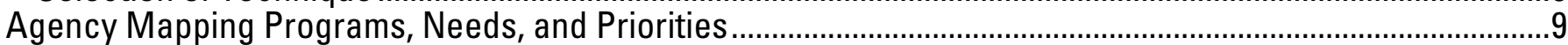

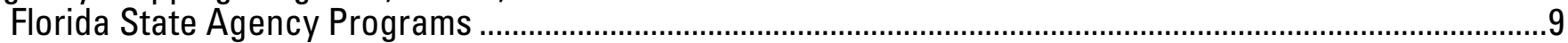

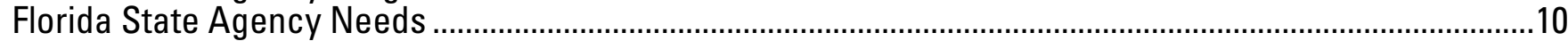

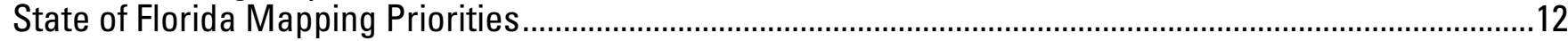

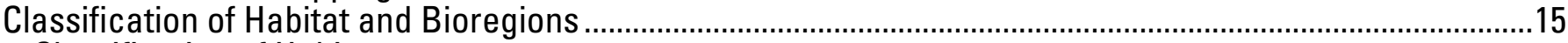

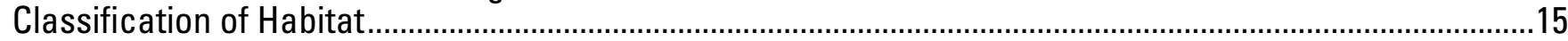

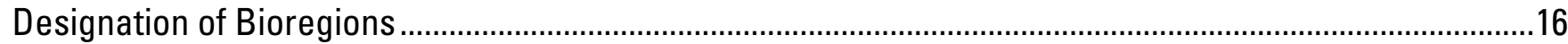

In-Depth Discussions: Matching Priorities to Next Steps.........................................................................20

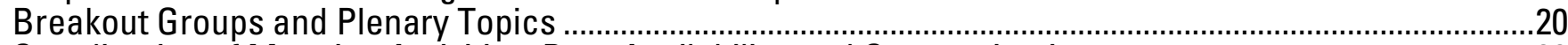

Coordination of Mapping Activities, Data Availability, and Communication ..................................................20

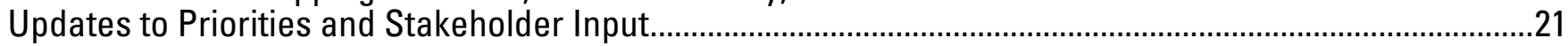

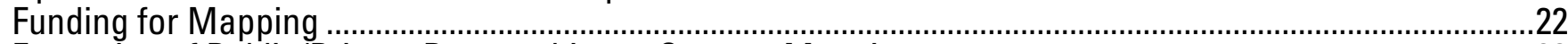

Formation of Public/Private Partnerships to Support Mapping .......................................................................23

Advantages and Disadvantages to Establishing a Single Federal Mapping Priority in Florida......................23

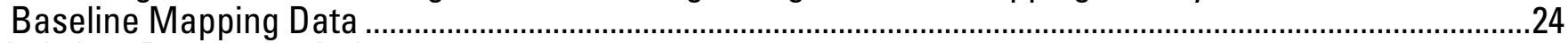

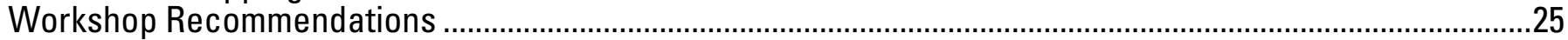

Finding Commonalities among Mapping Priorities ............................................................................25

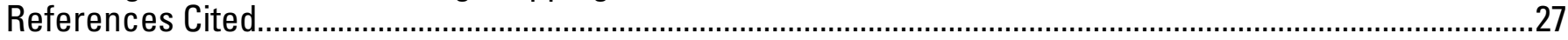

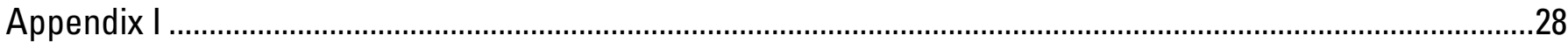

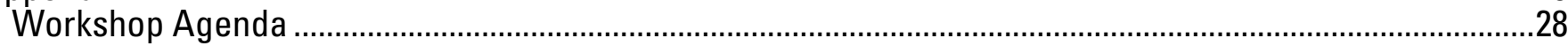

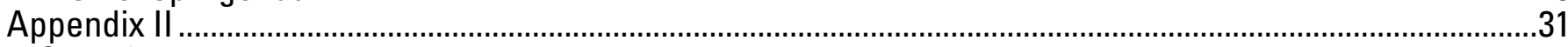

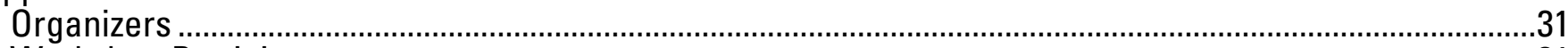

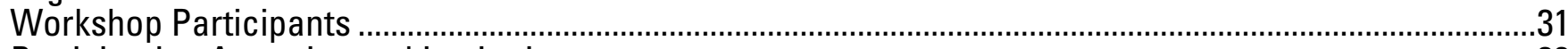

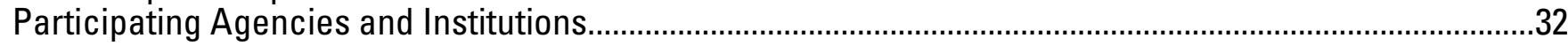




\section{Figures}

Figure 1. Shallow bathymetry of Fakahatchee Bay, FL, acquired with single-beam sonar (Locker, 2007) .......4

Figure 2. Examples of CHIRP seismic profile versus Boomer seismic profile (Flocks, 2007)

Figure 3. Acquisition-to-product data flow (left) and map showing USGS high-resolution seismic profiling 1990-2006 (right; Flocks, 2007).

Figure 4. Examples of NASA EAARL flight lines over the north Florida reef tract (Nayegandhi, 2007)

Figure 5. Examples of continuous resistivity profile (CRP) in Biscayne Bay, FL (Reich, 2007) ..........................7

Figure 6. Map showing numerical ranking of priority areas as scored by Florida State agencies.................12

Figure 7. Examples of marine zones: a) NERRS marine bioregions, b) workgroup geologic regions, c) basic bathymetric zones, and d) NOAA weather-forecast zones. ....

Figure 8. Florida marine-zones composite from NERRS bioregions, geology, bathymetry, and coastal weather zones.

Figure 9. Florida marine bioregions extrapolated from priority mapping areas and natural marine zones.....19

\section{Tables}

Table 1. State and Federal overlapping mapping needs.

Table 2. Priority mapping region by rank as scored by Florida State agencies, 2007.

Table 3. Minimum data required to address management issues in each priority area. 


\title{
Mapping of Florida's Coastal and Marine Resources: Setting Priorities Workshop
}

\author{
By Lisa Robbins, Steven Wolfe, and Ellen Raabe
}

\section{Executive Summary}

The importance of mapping habitats and bioregions as a means to improve resource management has become increasingly clear. Large areas of the waters surrounding Florida are unmapped or incompletely mapped, possibly hindering proper management and good decisionmaking. Mapping of these ecosystems is among the top priorities identified by the Florida Oceans and Coastal Council in their Annual Science Research Plan. However, lack of prioritization among the coastal and marine areas and lack of coordination of agency efforts impede efficient, cost-effective mapping.

A workshop on Mapping of Florida's Coastal and Marine Resources was sponsored by the U.S. Geological Survey (USGS), Florida Department of Environmental Protection (FDEP), and Southeastern Regional Partnership for Planning and Sustainability (SERPPAS). The workshop was held at the USGS Florida Integrated Science Center (FISC) in St. Petersburg, FL, on February 7-8, 2007. The workshop was designed to provide State, Federal, university, and non-governmental organizations (NGOs) the opportunity to discuss their existing data coverage and create a prioritization of areas for new mapping data in Florida. Specific goals of the workshop were multifold, including to:

- provide information to agencies on state-of-the-art technology for collecting data;

- inform participants of the ongoing mapping programs in waters off Florida;

- present the mapping needs and priorities of the State and Federal agencies and entities operating in Florida;

- $\quad$ work with State of Florida agencies to establish an overall priority for areas needing mapping;

- initiate discussion of a unified classification of habitat and bioregions;

- discuss and examine the need to standardize terminology and data collection/storage so that data, in particular habitat data, can be shared;

- identify opportunities for partnering and leveraging mapping efforts among agencies and entities;

- identify impediments and organizational gaps that hinder collection of data for mapping;

- seek innovative solutions to the primary obstacles identified;

- identify the steps needed to move mapping of Florida's oceans and coasts forward, in preparation for a better coordinated, more cost-effective mapping program to allow State and Federal agencies to make better decisions on coastal-resource issues.

Over 90 invited participants representing more than 30 State and Federal agencies, universities, NGOs, and private industries played a large role in the success of this two-day workshop. State of Florida agency participants created a ranked priority order for mapping 13 different regions around Florida. The data needed for each of the 13 priority regions 
were outlined. A matrix considering State and Federal priorities was created, utilizing input from all agencies. The matrix showed overlapping interests of the entities and will allow for partnering and leveraging of resources.

The five most basic mapping needs were determined to be bathymetry, high-vertical resolution coastline for sea-level rise scenarios, shoreline change, subsurface geology, and benthic habitats at sufficient scale. There was a clear convergence on the need to coordinate mapping activities around the state. Suggestions for coordination included:

- creating a glossary of terms: a standard for specifying agency data-mapping needs;

- creating a geographic information officer (GIO) position or permanent organizing group to maintain communications established at this workshop and to maintain progress on the issues identified during the workshop. The person or group could develop a website, maintain a project-status matrix, develop a list of contacts, create links to legislative updates and links to funding sources;

- developing a web portal and one-stop/clearinghouse of data.

There was general consensus on the need to adopt a single habitat classification system and a strategy to accommodate existing systems smoothly. Unresolved aspects of the systems warrant that a separate workshop would be needed to work out details.

Participants recognized that the State priority list would necessarily be updated periodically. An annual review of priorities would facilitate information exchange, mapping activities updates, and re-allocation of funding among changing priorities.

It was recognized that mapping of State waters would take billions of dollars and in light of tightening budgets there was need for processes that could be used to appropriate or leverage monies for mapping and reduce data-collection costs. Fourteen different avenues were explored. There was a clear consensus that the linking of public to private partnerships to support mapping was imperative, and ways to achieve this were discussed.

\section{Introduction}

Florida marine resource-management needs are increasingly critical in the face of global warming, sea-level rise, and maintaining the State economy. In their 2006-2007 Annual Science Report, the Florida Oceans and Coastal Council (FOCC) recognized that the comprehensive understanding of marine ecosystems needed to support management and restoration of resources and habitats depends upon reliable baseline data and ongoing data acquisition (FOCRC, 2007). Marine and nearshore habitat and resources on the Florida shelf are shaped by climatic, geologic, hydrologic and biologic processes interacting on a variety of scales from hundreds of kilometers (e.g., groundwater flow, climate change) to millimeters (e.g., microbial communities, benthic invertebrates). Nutrient loading, environmental resources, the health of biological communities, red tides, submarine springs, and fisheries management are some of the current issues (FOCRC, 2008).

One of the significant gaps in baseline data in Florida coastal and marine areas is the lack of coordination and development of comprehensive maps and other datasets that delineate bathymetry, substrate, habitat, and biological and natural resources. This information is critical for managers to understand the environment, its change through time, and the impacts of natural and anthropogenic processes on the marine environment. A variety of technologies is needed to map everything from deepwater habitats to very shallow areas. Data are needed for resource management, large-scale models, fisheries models, and habitat characterization.

Florida has over $210,000 \mathrm{~km}^{2}$ of coastline and marine shelf areas. Although some bathymetric and seafloor data exist for the coast and shelf of Florida, most data-collection efforts were project-driven and 
specific to the needs of a particular study. As a result, existing datasets may be available for limited areas, difficult to obtain, in analog or older digital formats, at a variety of spatial resolutions, inconsistent in data quality, and maintained by many different agencies and research groups.

A comprehensive mapped dataset is needed for the coast and shelf of Florida, but there are no priorities established among the various agencies and academic institutions on how to tackle such a huge mapping endeavor. Agencies and research institutions currently lack a distribution method or a communication pattern to share knowledge of existing data or common mapping needs. The primary advantages of inter-agency collaboration are:

- comprehensive data compilation;

- identification of data-rich and data-poor regions;

- coordination of data distribution and publication;

- alliance for technical expertise, available equipment, and development of new technologies;

- coordination of ongoing and future projects, including funding procurement.

Because of the enormity of the area, mapping of the priority areas in their entirety must likely be a phased approach, including acquisition of a variety of data that will be utilized in defining Essential Fish Habitat (EFH), wetland, sea grass, live rock, coral habitats, etc. These data in turn will be used as the baseline to conduct sustained observations of integrated physical and biological parameters and to develop user-friendly biophysical models for research and management applications, such as conservation and restoration.

\section{Mapping-Workshop Goals}

To address State mapping needs, USGS, FDEP and SERPPAS cosponsored a workshop, Mapping of Florida's Coastal and Marine Resources: Setting Priorities, 6-8 February 2007, St. Petersburg, FL. See Appendix I for the workshop agenda and the Florida Regional Marine Mapping website for detailed presentations and minutes from the workshop (http://www.dep.state.fl.us/MarineMapping/workshops/; FDEP, 2007). The overall workshop objective was to give State, Federal, university, and NGO participants the opportunity to discuss existing data coverage, available technologies, and to prioritize areas for acquiring new map data. Organizers, participants, and agencies are listed in Appendix II. Specific goals of the workshop were to:

- give participants an overview of new mapping technologies;

- have participants gain knowledge of current mapping programs, agency needs and priorities;

- begin an initial identification of mapping commonalities among agencies;

- identify and designate State of Florida mapping priorities;

- begin discussing the coordination and matching of technologies;

- discuss the classification of habitats and bioregions;

- discuss next steps.

The workshop included presentations on technology and agency needs and priorities followed by participant discussions in breakout groups. The workshop report is divided into technology, agency programs, needs and priorities, habitat and bioregion classifications, in-depth discussions, and workshop recommendations.

\section{Mapping Technology, Scales, and Resolution}

Desired outcomes of this workshop included the prioritized mapping needs of the State, promotion of communication between agencies with similar and/or overlapping mapping needs, and facilitation of the development of a comprehensive baseline dataset for the Florida shelf. The technology section of the workshop was designed to introduce and hold open discussion on the variety of mapping technologies available, the types of products already in production, and a vision for integrating these products in a thorough and practical view of the marine and coastal resources of the Florida shelf. The various platforms 
and techniques offer a number of spatial-, spectral-, and temporal-resolution options. Cost and processing time also play important roles in the course of decision-making prior to data acquisition. Communication among scientists, technical experts, and managers can facilitate selection of the appropriate mapping application for the data quality required, while factoring fiscal responsibility and expediency into the equation. The mapping-technology section serves as a platform for expanded discussions for determining viable data-acquisition procedures and development of new and innovative mapping products for the Florida shelf and coastline.

\section{Technology}

Mapping technology can be classified by data type, sensor, platform, or product. Products can be further categorized by scale, resolution, and format. Several mapping-technology topics were discussed during the workshop: bottom and subbottom acoustics, remote-sensing and imaging techniques, the application of autonomous underwater vehicles (AUVs) to mapping bottom characteristics, and new mapping techniques.

\section{Vessel-based Acoustic Sensors}

Acoustic sensors rely on sonar (SOund Navigation and Ranging) technology to identify and map water-column, bottom and subbottom characteristics. The sensors are typically mounted on sea-going vessels, and data are collected along 'track lines.' Trackline data are subsequently used to create map products. Examples of sonar systems for bottom mapping were presented: sidescan-sonar imaging systems, swath and single-beam bathymetric mapping systems, acoustic-classification techniques, and seismic-reflection profiling. Resolution of the bathymetric data is dependent on the physical environment, sensor type, and trackline spacing. Single-beam sonar is effective for mapping bathymetry in shallow water, and swath multi-beam is used in deeper environments (Fig. 1).

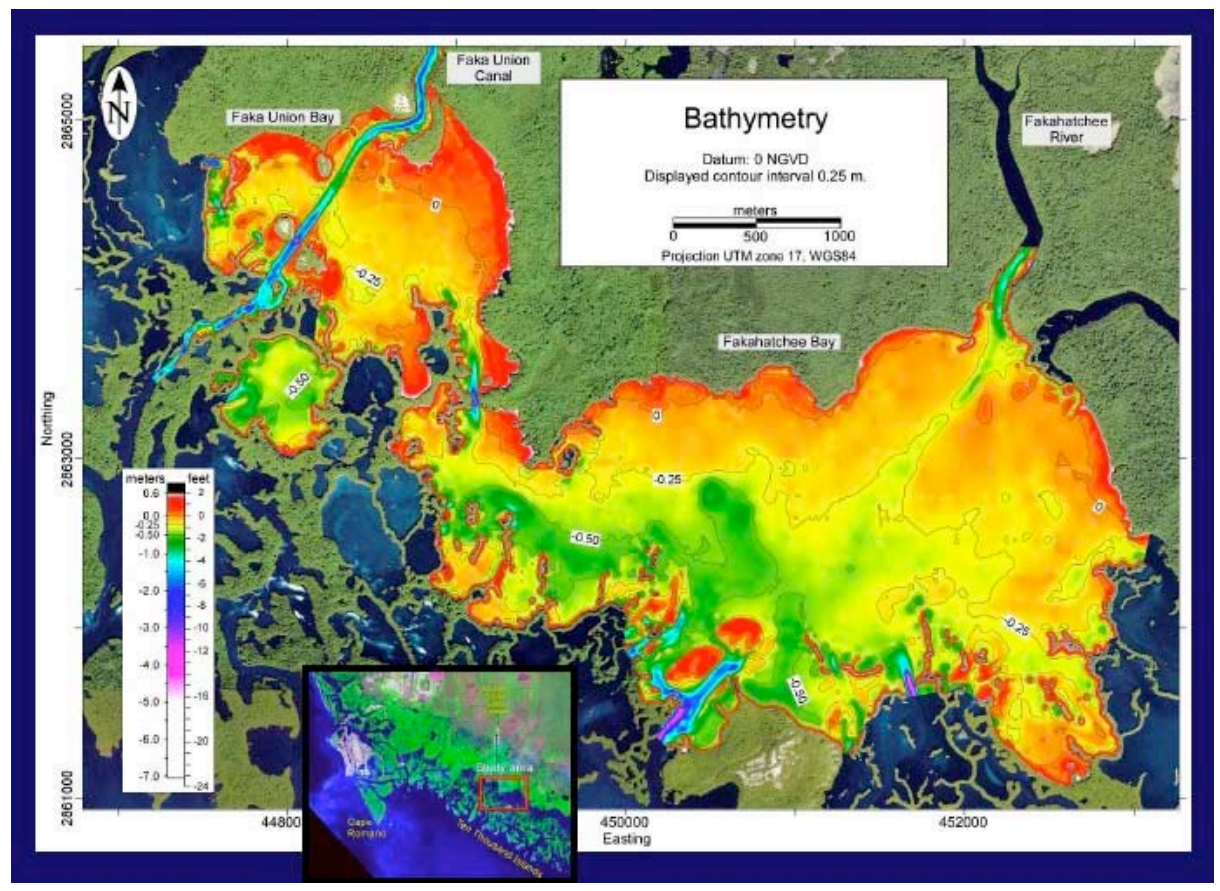

Figure 1. Shallow bathymetry of Fakahatchee Bay, FL, acquired with single-beam sonar (Locker, 2007)

Seismic-reflection profiles provide information on the characteristics of the geology underlying the seafloor. Two commonly used seismic systems, CHIRP and Boomer, apply different frequency and power ranges. The CHIRP seismic system acquires profile data at a 1-m vertical resolution with 50-m penetration 
as opposed to the Boomer system, which acquires 1- to 3-m vertical resolution with 100-m penetration (Fig. 2). USGS high-resolution seismic profiling (HRSP) data have been acquired at several locations around the State of Florida (Fig. 3).

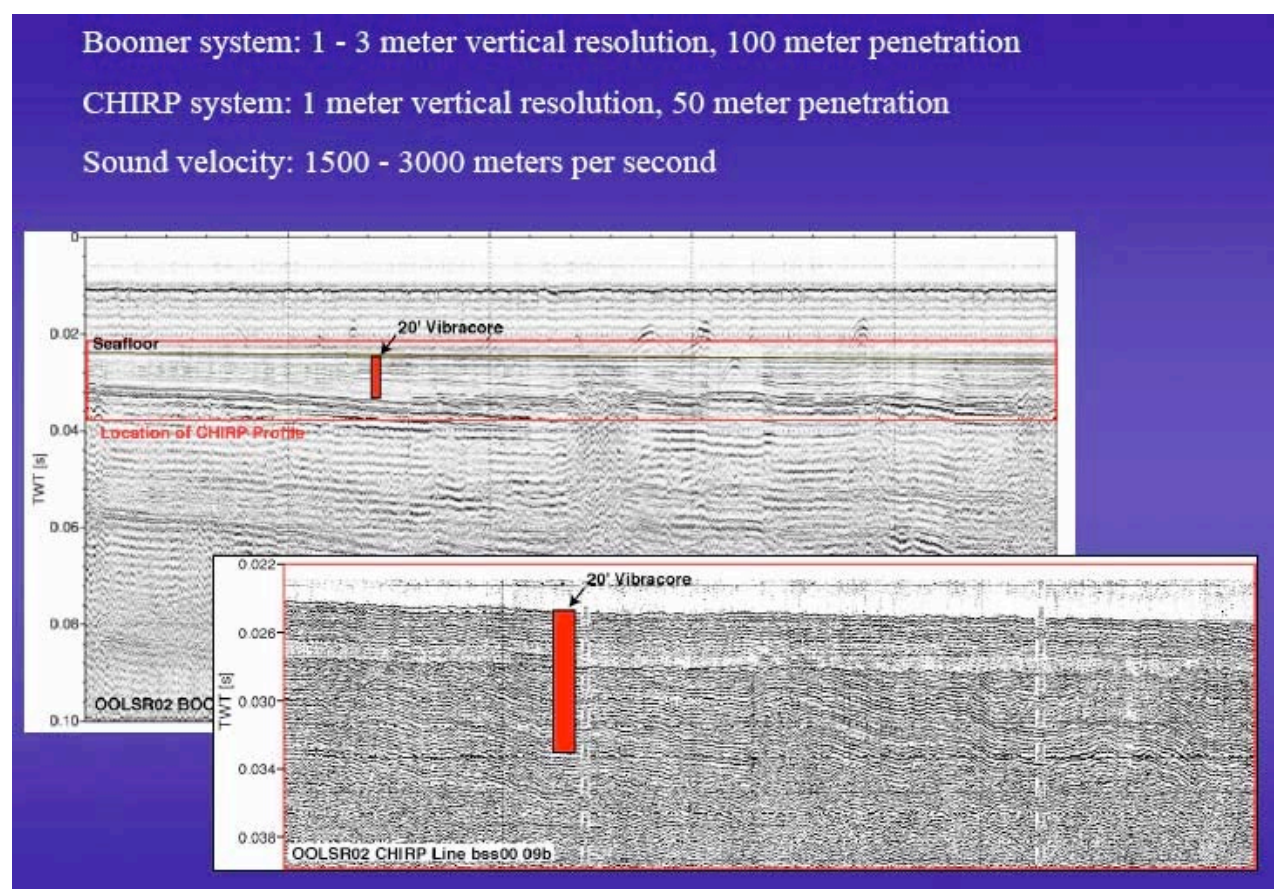

Figure 2. Examples of CHIRP seismic profile versus Boomer seismic profile (Flocks, 2007)

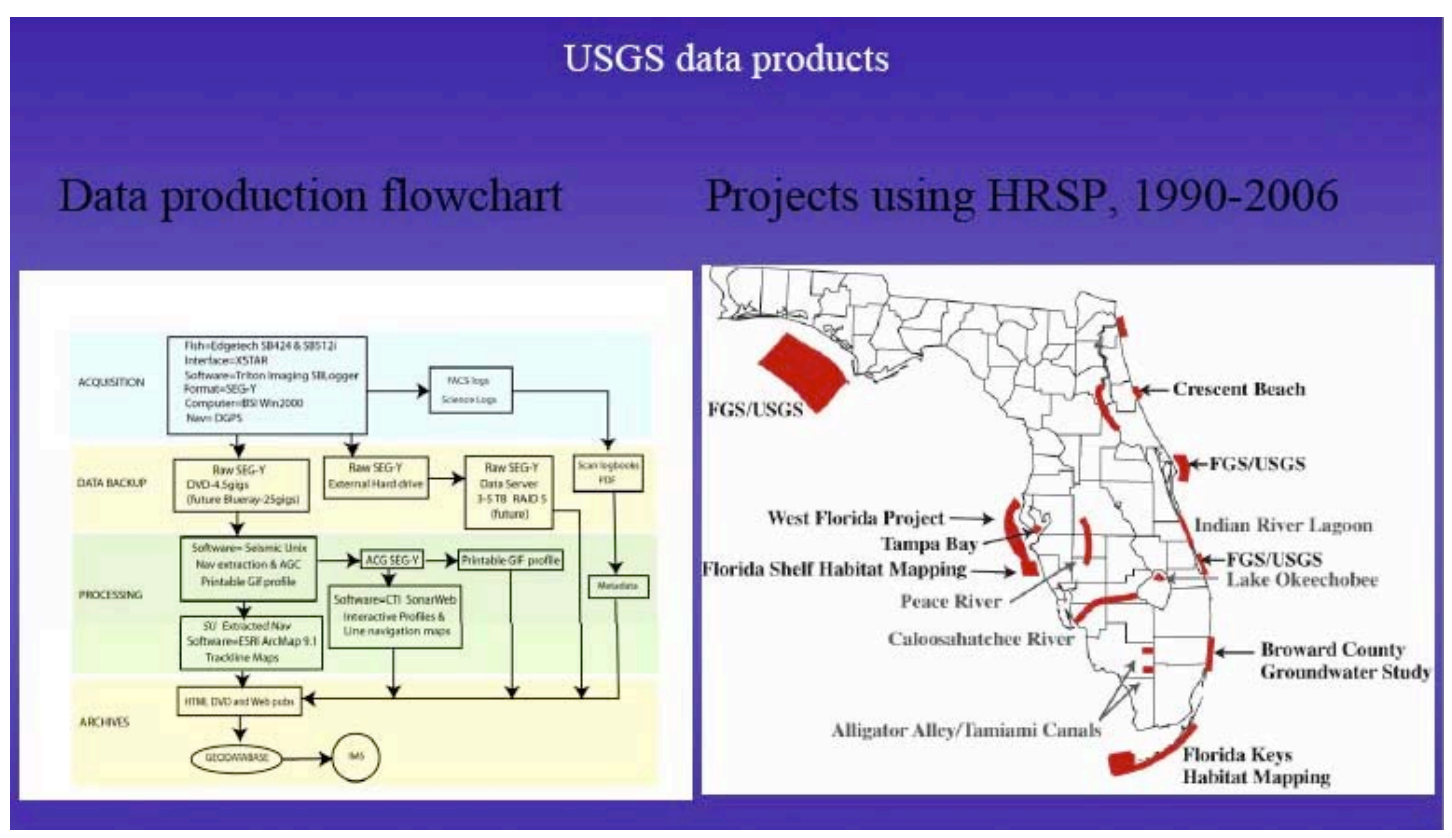

Figure 3. Acquisition-to-product data flow (left) and map showing USGS high-resolution seismic profiling 1990-2006 (right; Flocks, 2007) 


\section{Vessel-Based Non-Acoustic Data}

Non-acoustic data-collection instruments (optical, images, samples) can also be deployed from sea-going vessels. USGS researchers presented examples of two vessel-mounted geo-referenced imaging systems: 1) Along-Track Reef-Imaging System (ATRIS) and 2) Deep ATRIS. Photos and videos of bottom features and habitat snapshots make it possible to create a record of seafloor characteristics tied directly to a Geographic Information System (GIS). Sampling systems include, but are not limited to, bottom samplers, drill rigs, and water samplers. These systems can be deployed to "ground truth" data collected from an imaging or sonar system.

\section{Remote-Sensing Platforms}

Remote-sensing methods can be used to map both marine and coastal features. They include LIght Detection And Ranging (LIDAR, a.k.a. laser altimetry) and satellite and airborne-imaging systems. Both passive and active sensors can be deployed on aircraft or satellite to collect measurements and images. Depending on the sensor, altitude, and optical depth, airborne data can be collected for sea-surface characteristics, water-column quality, water depth, and seafloor characteristics such as habitat type and cover.

Researchers from the U.S. Army Corps of Engineers (USACE) and USGS gave examples of laser altimetry using the Compact Hydrographic Airborne Rapid Total Survey (CHARTS) and Experimental Advanced Airborne Research Lidar (EAARL; Fig. 4). Both the CHARTS and EAARL systems extend the collection of surface-data points from onshore to offshore, providing both topographic- and bathymetricsurface models. The topographic/bathymetric systems can be used successfully under low-turbidity, lowwave conditions. These systems facilitate mapping of shallow coastal areas where deep-draft vessel-based bathymetric systems are constrained.

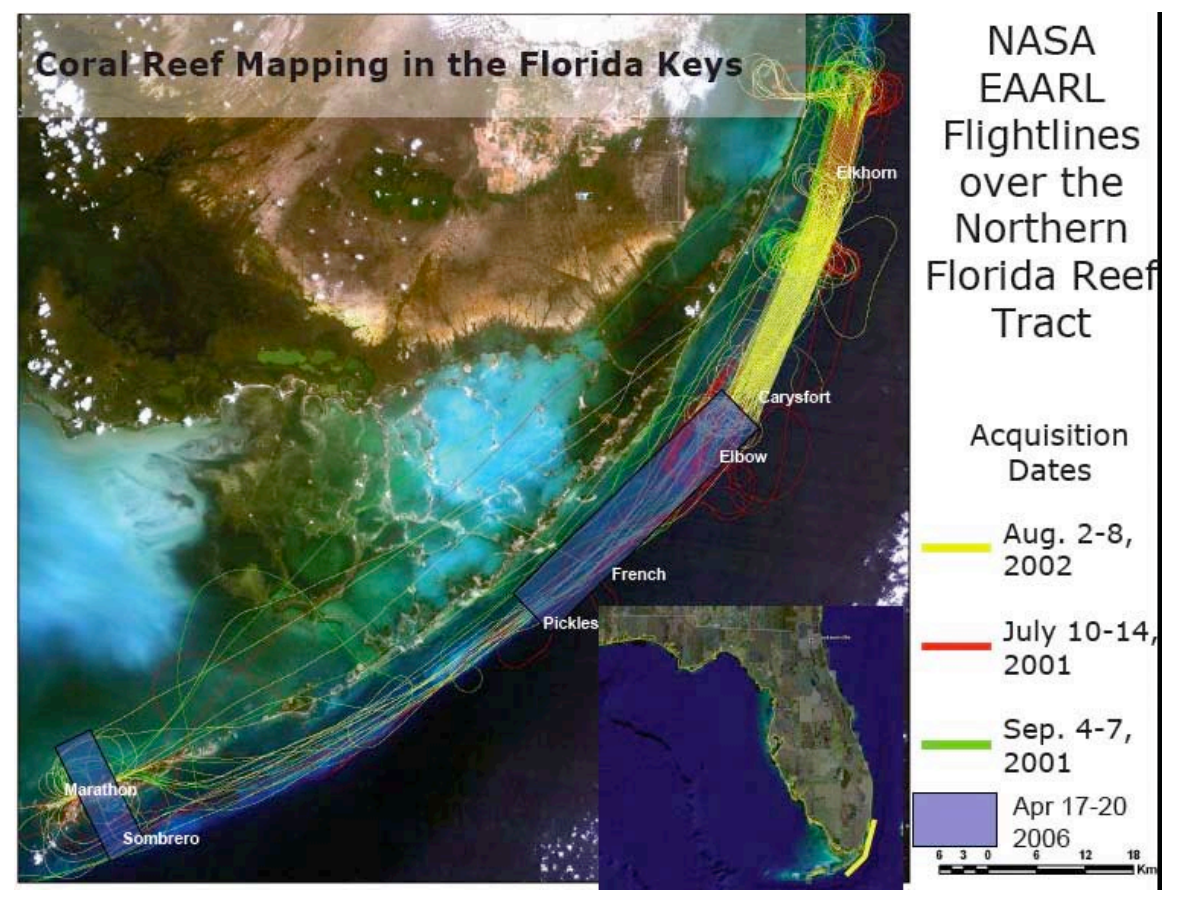

Figure 4. Examples of NASA EAARL flight lines over the north Florida reef tract (Nayegandhi, 2007)

Researchers from the University of South Florida (USF) and Florida Department of Environmental Protection (DEP) provided examples of airborne and satellite sensors used to map water quality and habitat. The digital compact airborne spectrographic imager (CASI) acquires hyperspectral image data for mapping water-column and benthic-habitat information and can be used to develop classification maps at 
local to regional scales. Satellite imagery, on the other hand, can provide large synoptic habitat information and time series of water column and ocean bottom.

Aerial photography has been used for years to map coastal habitats such as seagrass beds. Optical remote sensing provides a cost-effective synoptic view of many ecosystems around Florida. However, depending on the science question, optical remote sensing may lack the spatial or spectral information to adequately address the question posed.

\section{Remotely Operated Vehicles}

Researchers from the USF Center for Ocean Technology (COT) and Florida Atlantic University (FAU) SeaTech presented applications using remotely operated vehicles (ROVs) as mapping platforms in marine environments. A mobile inspection package (MIP) used on an autonomous underwater vehicle (AUV) or ROV provides a unique opportunity to produce micro-bathymetric maps (less than 1m detail) for mapping water-column information and to map benthic or subbottom habitats.

\section{New Mapping Technologies}

The final set of presentations covered new mapping techniques and applications. The hybrid mapping tool (HMT), presented by Nova Southeastern University (NSU) researchers, uses advanced processing techniques and edge detection for raster-image data, such as LIDAR, sidescan, and multibeam, to classify submerged features. The automated process searches for differences in habitat architecture and complexity measures. The technique relies on geomorphic properties more than spectral properties and may be useful for categorization and change detection.

A presentation was also given by USGS researchers on methods in mapping electronic resistivity, a technique used to map groundwater discharge in nearshore areas. Products are derived from both continuous or stationary resistivity technology. The inverted resistivity sections in the final product reveal geologic or hydrologic targets. The location of less saline, or more resistive, water can be used to identify wastewater outfalls, aquifer seeps, or change over time (Fig. 5).

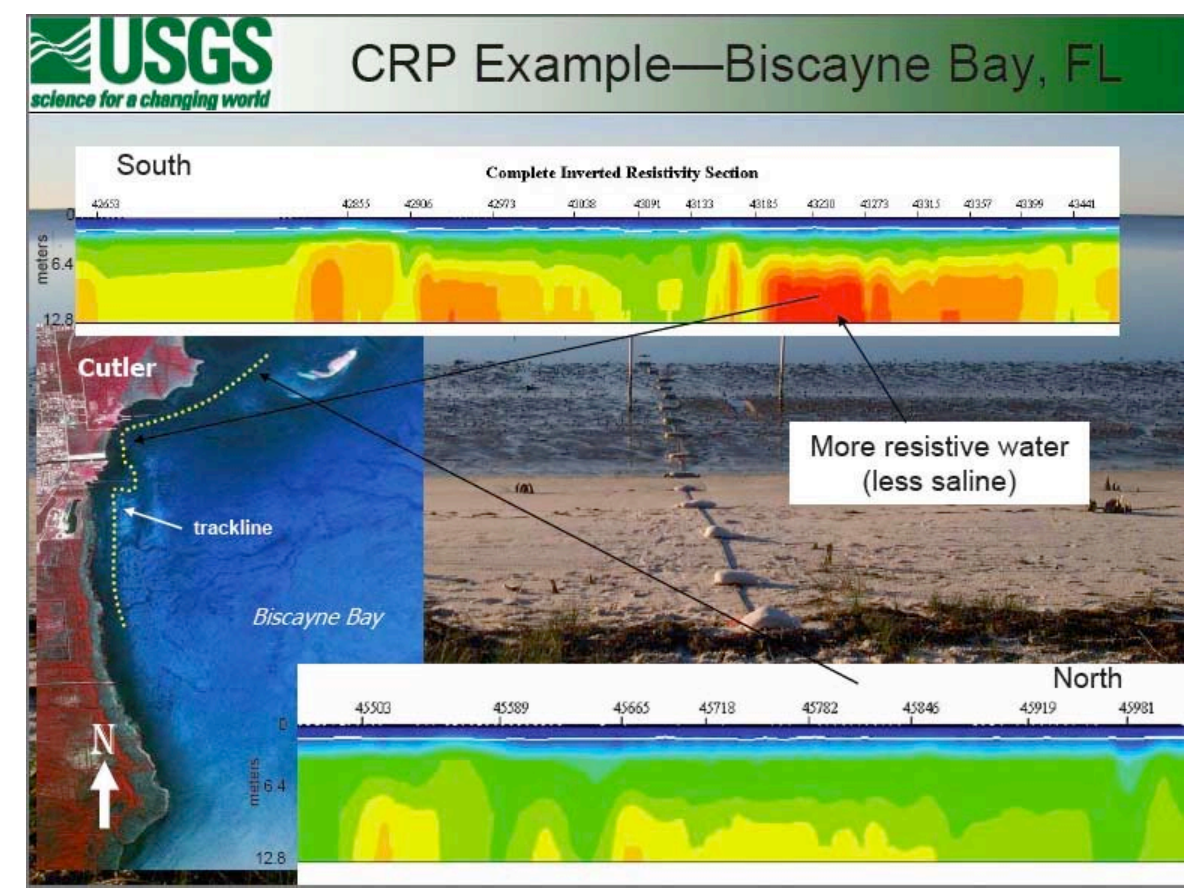

Figure 5. Examples of continuous resistivity profile (CRP) in Biscayne Bay, FL (Reich, 2007) 


\section{Selection of Technique}

Technologies are available to address most mapping needs in shallow, mid-shelf, and deep-shelf regions but may be cost prohibitive. Traditional marine-mapping technology has been inadequate to address large-scale mapping of seafloor in shallow, turbid waters. For these areas, it is possible to map locally, using small boats and acoustic sensors. Airborne sensors have traditionally been used for mapping in optically shallow waters. With proper preparation and a short lead time, it is feasible to map shallow regions with airborne sensors during low-wave, low-turbidity conditions.

Each technology comes with constraints on coverage (scale), resolution, data type, and data quality. Selection of the mapping method should be evaluated for cost-effectiveness, depending on funds, time, and expertise available. The State of Florida is in a position to establish methods, new approaches, and cooperative efforts that capitalize on available resources to produce comprehensive coverage of marine and coastal resources.

Several existing websites provide management information on mapping technology (USGS, 2008). The Alliance for Coastal Technologies (ACT) has an online compilation of technologies (ACT, 2008). This site is sponsored by NOAA and several research groups and was recognized as a reasonable place to start gathering information for a decision diagram for selection of appropriate mapping techniques.

A comprehensive list of information on all mapping technologies, including resolution and cost, would be useful. NOAA has an informative compilation of information in its publication "Mapping Southern Florida Shallow-Water Coral Ecosystems: An Implementation Plan" (Rohmann and Monaco, 2005). This document provides information on technologies and cost-per-unit data. Relevant tables in Rohmann and Monaco (2005) may serve as sources of information and as the basis for further refinement. Participants suggested that a lead agency develop a matrix (template) to match mapping and management needs with technologies. It was suggested that this matrix would be web-based and interactive in a "flowchart" manner. Action: Create online matrix of technologies decision tree, where vendors can enter prices. The technology breakout group developed preliminary lists to illustrate and highlight technical capabilities and applications.

\section{Example platforms, sensors, and resolution}

\section{SEA SURFACE}

- Platform - vessel, satellite, airborne, diver

- Sensors - acoustic, active and passive optical, chemical, thermal, magnetic (2D, 3D), and direct sampling (physical)

- Products - bathymetry, imagery, geology, water quality, and water parameters

- Resolution - sub-meter to tens of meters

- Scale - meters to tens of kilometers, subsurface

SPACE

- Platform - satellite

- Sensors - optical (multi-hyperspectral), radar, and thermal

- Products - sea-surface temperature and height (SST/SSH), color, habitat, photo, currents, winds, and evaluation of trends

- Resolution - meters to kilometers

- Scale - hundreds of kilometers

- Practicality - global, 24-hour, synoptic, time series

- Limitation - parameters are pre-set on most satellite/sensor packages 
- Platform - planes, helicopter, balloon

- Sensors - active and passive optical, thermal, atmospheric, laser, magnetic (2-D, 3-D), radar, multiand hyper-spectral

- Products - bathymetry/topography, habitat, imagery, water quality, currents, species monitoring; suitable for shallow and coastal mapping

- Resolution - sub-meter to tens of meters

- Scale - kilometers to hundreds of kilometers

- Practicality - regional, day and nighttime depending on sensor, sensor flexibility

- Limitation - weather, optical depth

Example projects and geographic regions:

Shallow habitat such as seagrass beds

- Technologies - photo interpretation, bathymetry (2-3 m), LIDAR, sidescan sonar, airborne hyperspectral imagery, satellite imagery, and direct sampling

- Problems - shallow depths, weather, cost/time

- Methods under development - unsupervised interpretation (hybrid mapping tool)

- Product - GIS layer, virtual reality mark-up language (VRML), benthic-habitat map

Mid-depth such as coral reef (20-m water depth)

- Problems - fringe of passive optical, too shallow for SWATH

- Technologies - active (LIDAR) and passive (aerial or vessel-based) remote sensing, ROV, and divers

Mid/deep water such as Pulley Ridge

- Problems - 3D (water column, volume), distance (x,y,z) ground truth, resolution, cost

- Technologies - acoustic, multibeam, sidescan, bottom class, optical (video, AUV)

- Bottom line - a number of options are available. The underlying science is key to determining the method, although cost effectiveness often plays an integral role.

\section{Agency Mapping Programs, Needs, and Priorities}

Florida State agencies, Federal agencies, local governments, municipalities, and academic institutions have been acquiring data and mapping coastal and marine resources for many years. However, each agency has jurisdiction over different regions, and each is driven by a different mandate. Currently, there is no centralized database repository, metadata for existing data are incomplete, and the community has lacked a forum. In an effort to address data gaps, resource limitations, and the 'need to know,' a segment of the workshop was devoted to the various ongoing programs.

\section{Florida State Agency Programs}

Agencies that presented their programs and mapping priorities at the workshop included the Florida Fish and Wildlife Conservation Commission (FWC), FDEP, Department of Agriculture and Consumer Services (DACS), Northwest Florida Water Management District (NWFWMD), St. Johns River Water Management District (SJRWMD), Southwest Florida Water Management District (SWFWMD), South Florida Water Management District (SFWMD), Suwannee River Water Management District (SRWMD), National Estuary Program (NEP), USGS, NOAA, National Marine Fisheries Service 
(NMFS), National Park Service (NPS), The Nature Conservancy (TNC), and the U.S. Army Corps of Engineers (USACE).

The FWC Fish and Wildlife Research Institute (FWRI) have initiated a cataloging effort called Geospatial Assessment of Marine Ecosystems (GAME). FDEP and FWRI partnered with the University of South Florida (USF) and Florida Institute of Oceanography (FIO) to create the GAME program in 2005 as the initial step of a mapping initiative. This step has focused on assessing the physical, chemical, geological, biological, and human-use data available for resource management as a means to identify where gaps in the different types of data exist. The GAME program has established a database of metadata for existing map data and has produced data maps showing relative densities of available data of various types. The catalog does not provide access to actual data and is limited by a lack of submissions from possible data sources.

\section{Florida State Agency Needs}

Although mapping needs among Federal, State, and local agencies are diverse, there are common and basic underlying needs. Best use of fiscal resources will depend on coordination and leverage efforts and a comprehensive catalog of ongoing and future projects to avoid duplication. The most common marine mapping information needs discussed were:

- bathymetry: varying vertical and spatial resolutions, depending on location and depth;

- sea level: nearshore high-resolution bathymetry and topography merge;

- shoreline change;

- benthic habitat maps;

- subsurface geology;

- sediment;

- human structures: docks, pipelines, cable;

- water quality: nutrients, organic matter.

Eight State agencies and four Federal agencies outlined participants in their programs, mapping needs, and priorities. A matrix of State and Federal needs was created (Table 1) from the presentations and discussions. In this exercise, topics of concern were simply listed and checked if an agency indicated the topic or area was a priority. The topic list included broad, regional concerns and recognized local features such as habitat areas of particular concern (HAPC). Localities or topics that had multiple-agency interest have greatest potential for leveraging the full extent of resources. For example, the Big Bend Seagrasses Aquatic Preserve (from St. Marks to Crystal River) shows five agencies are interested in mapping this area. Biscayne Bay and Northwest Florida also show five agencies interested in mapping the areas. This matrix provides a view into overlapping needs of agencies and shows the potential for elimination of redundancies in mapping of certain areas and leveraging monies.

Table 1. State and Federal overlapping mapping needs.

\begin{tabular}{|c|c|c|c|c|c|c|c|c|c|c|c|c|c|c|c|c|}
\hline Mapping Area & 帒 & 㞻 & $\begin{array}{c}\mathscr{y} \\
\mathbf{a} \\
\mathbf{a}\end{array}$ & 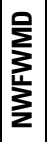 & $\sum_{\substack{\text { s. } \\
\text { 号 }}}$ & 号 & $\sum_{\frac{1}{5}}^{0}$ & 눈 & 出 & 息点 & $\sum_{\mathbf{Z}}^{\mathbf{u}}$ & 这 & 늘 & 岂 & 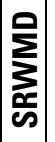 & Sum \\
\hline \multicolumn{17}{|l|}{ Broad areas/localities } \\
\hline Areas of "harder" bottom types indicated in 2004 INSTARR & & & & & & & & & & & & & $X$ & & & 1 \\
\hline Deep-water hardbottom & & & & & & & & & & & $\mathrm{X}$ & & & & & 1 \\
\hline Areas indicated in Benthic Complexity model (not already & & & & & & & & & & & & & $X$ & & & 1 \\
\hline Areas offshore previously mapped seagrass beds (GOM beyond & & & & & & & & & & & & & $X$ & & & 1 \\
\hline Estuaries, tidal inlets, and wetlands & $X$ & & & & $\mathrm{X}$ & & $\mathrm{X}$ & & $X$ & & & & & & $X$ & 5 \\
\hline Entire Florida coastline with LIDAR & & & & $\mathrm{X}$ & $\mathrm{X}$ & & & & & & & & $X$ & & $X$ & 4 \\
\hline Gulf-wide bathymetry & & & & & & & & & & & $X$ & & & & & 1 \\
\hline Nearshore & & & & & & & & & & & $X$ & & & & & 1 \\
\hline GOM reefs - shallow and deep & & & & & & & & & $x$ & & & & $X$ & & & 2 \\
\hline
\end{tabular}


Table 1. continued

\section{Mapping Area}

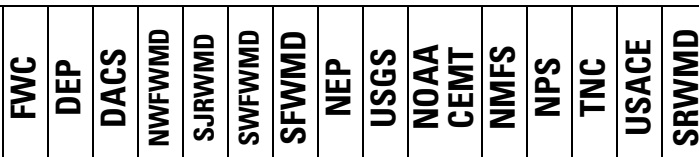

\section{Specific locations}

Aquatic Preserves

\begin{tabular}{l|l|l|l}
$X$ & $X$ \\
$X$ & $X$
\end{tabular}

\begin{tabular}{l|l|l|l|l|l|l}
$X$ & $X$ & $X$ \\
\hline & $X$ & $X$ \\
\hline
\end{tabular}

Big Bend including Ochlockonee Shoals

\begin{tabular}{l|l|l|l|l|l|l} 
& $X$ & $x$ & $x$ \\
\hline & & &
\end{tabular}

Big Bend Sea Grass Aquatic Preserve - St. Marks to Crystal River

Biscayne Bay

Caloosahatchee River

\section{$\mathrm{X}$}

Charlotte Harbor

Charlotte Harbor to Estero Bay, coastal

Charlotte Harbor-Estero Bay, southern

Clearwater/St. Joseph Sound to southern Charlotte Harbor-Estero

Dry Tortugas NP

Estero Bay

Everglades, western

Florida Bay

Florida Keys

Florida Keys, greater

Indian River Lagoon

Loxahatchee River

North/central east coast, Fed. waters offshore, FL state line

NE FL in the Jacksonville area, shelf-edge structures

NE Florida wetlands

NE Florida reefs (coral and oyster)

NE shelf (Canaveral north to Georgia border)

NW FL DeSoto Canyon edge (Lophelia reefs offshore from the

NW Florida Oculina banks

NW Florida nearshore - within $1 \mathrm{~km}$ of shore

NW Florida estuaries

NW Florida deep water

NW Florida, Federal waters offshore Santa Rosa and Okaloosa

Sarasota Bay

SE Florida (Martin, Palm Beach, Broward, and Dade)

South Florida reefs

Springs Coast

SW FL - St. Petersburg to Cape Sable, including Pulley Ridge and

SW FL, deep areas (Lophelia reefs offshore Oculina HAPC)

SW Florida - nearshore

Exclude SW Florida - Flagler County, southern offshore State

Tampa Bay

The Marquesas Keys

West Florida shelf

West Florida shelf - Pulley Ridge northward

\begin{tabular}{l|l|l|l|l|l|l|l|l|l} 
& & $X$ & $X$ & & $X$ & & & & 3 \\
\hline$X$ & & & & & & & & & \\
\hline
\end{tabular}

Panhandle AL/FL to Port St. Joe

West Florida Tarpon Springs to Naples

East coast Virginia Key to FL/GA border

St. Marks to Crystal River- nearshore freshwater springs

Northeast coastal basins (north of Jacksonville)

Sebastian River 


\section{State of Florida Mapping Priorities}

State-appointed representatives created an initial prioritization list through a process known as "paired comparisons," in which each potential priority mapping area was compared to every other priority. The preliminary list was later refined by a larger, more inclusive group of State agency representatives to incorporate information from the workshop into the priority setting. All eight State agencies with coastal and ocean resource-management responsibilities, including all five water-management districts, FDEP, FWC, and DACS, provided input to the process. Results of that effort are shown in Table 2 and Figure 6.

Table 2. Priority mapping region by rank as scored by Florida State agencies, 2007.

\begin{tabular}{rlc} 
Rank & \multicolumn{1}{c}{ Mapping Region } & Cumulative Score \\
1 & Big Bend & 77 \\
2 & NW Florida & 71 \\
3 & Indian River & 59 \\
4 & Florida Keys/Dry Tortugas & $\mathbf{5 8}$ \\
$5^{*}$ & Charlotte Harbor & $\mathbf{5 4}$ \\
$5^{*}$ & Springs Coast & $\mathbf{5 4}$ \\
$7^{*}$ & NE Florida & $\mathbf{4 6}$ \\
$7^{*}$ & 10,000 Islands & $\mathbf{4 6}$ \\
9 & Florida Bay & $\mathbf{4 0}$ \\
10 & SE Florida & 35 \\
11 & Tampa & $\mathbf{3 1}$ \\
12 & W Florida shelf break & 30 \\
13 & Oculina banks & 19 \\
& $*$ indicates a tie between two priority regions
\end{tabular}

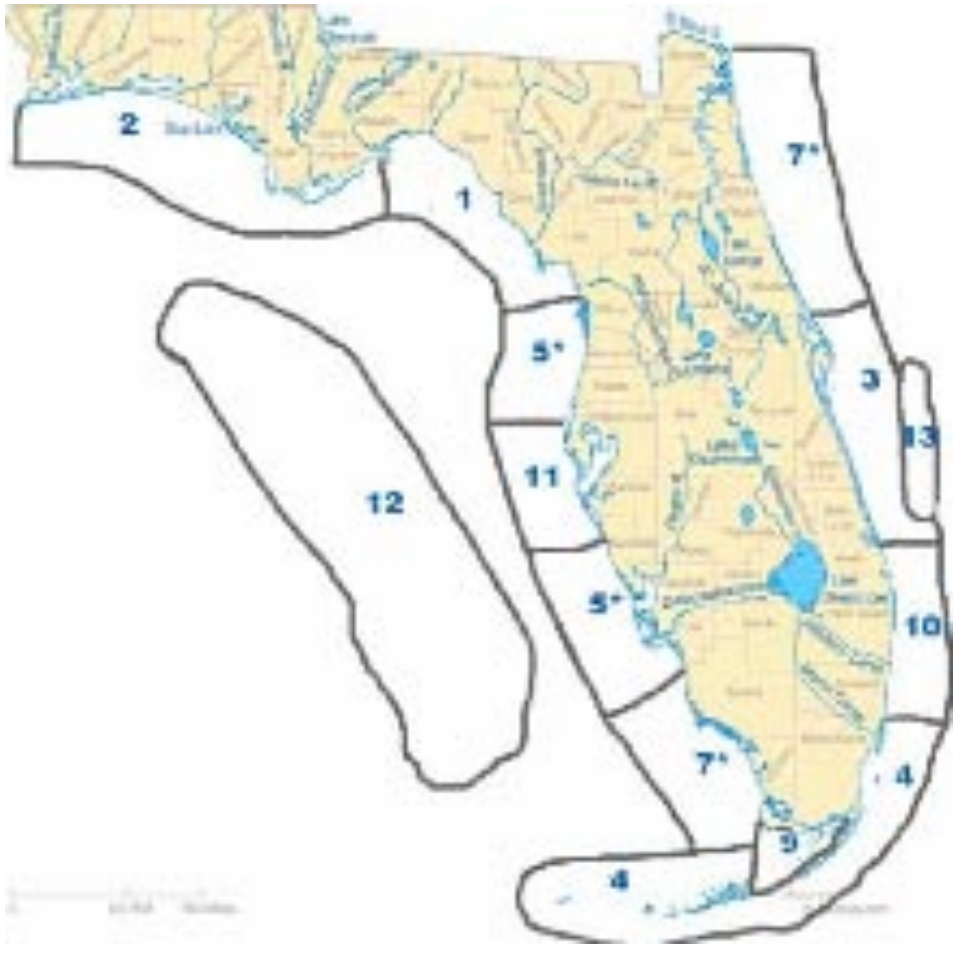

Figure 6. Map showing numerical ranking of priority areas as scored by Florida State agencies. 
The top two ranking mapping-priorities areas are Big Bend and NW Florida. The issues driving the need for mapping in these two places include:

- each area contains large Aquatic Preserves;

- anticipated changes in land-use patterns;

- need for shoreline-change detection;

- presence of emergent coastal wetlands;

- many benthic features are poorly known;

- fisheries management such as Gulf sturgeon habitat usage;

- legislation that allows for no degradation of habitat beyond ambient conditions.

These two areas also lack a number of newer data acquisitions and have been relying on older datasets to address pertinent management questions. Managers need detailed bathymetry, maps of bottom type and submerged aquatic vegetation (SAV), and the ability to delineate Marine Protected Areas (MPAs). The workgroup developed a table listing the minimum data needed to address management needs and suggested resolution, scale, and technology (Table 3).

Table 3. Minimum data required to address management issues in each priority area.

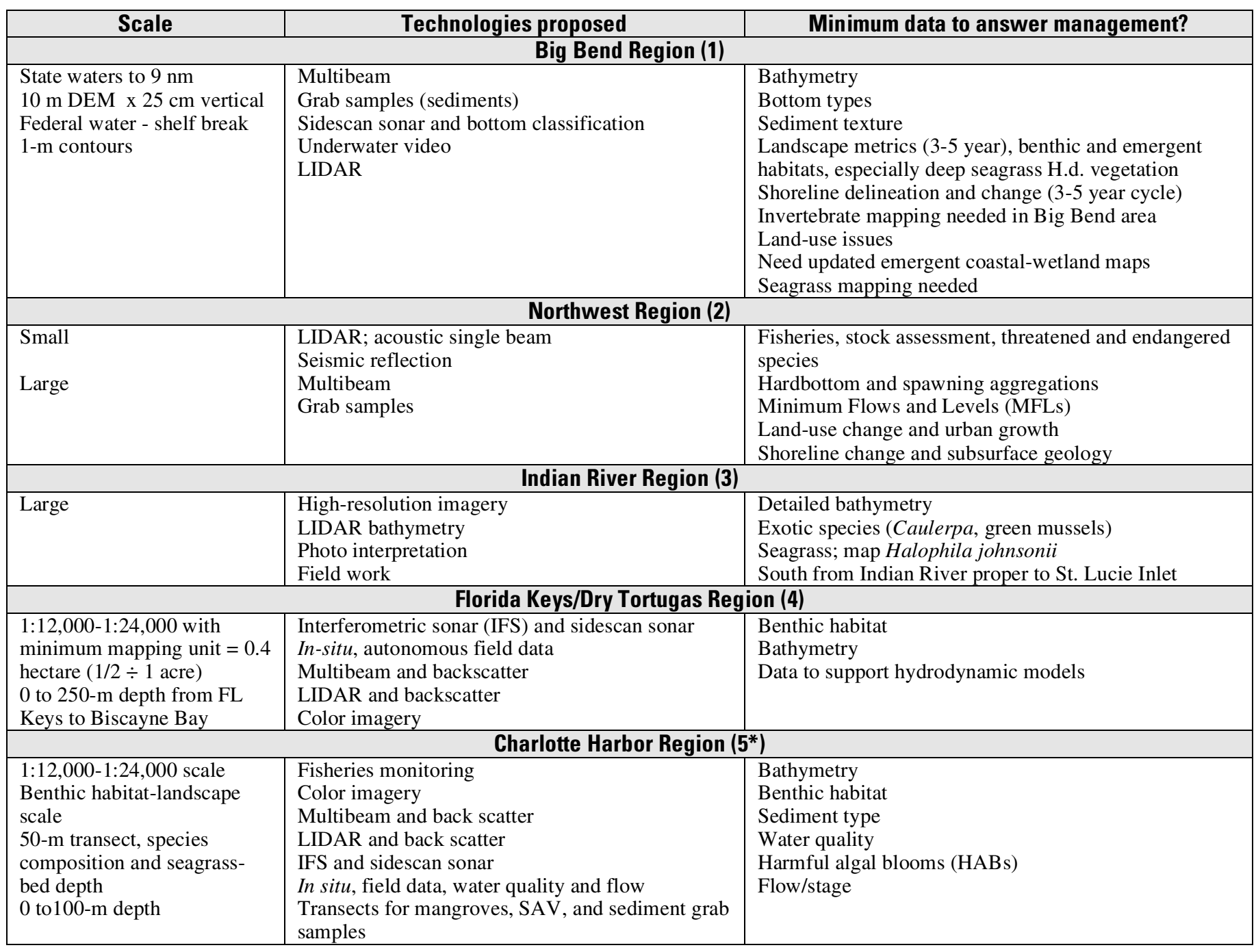


Table 3 continued

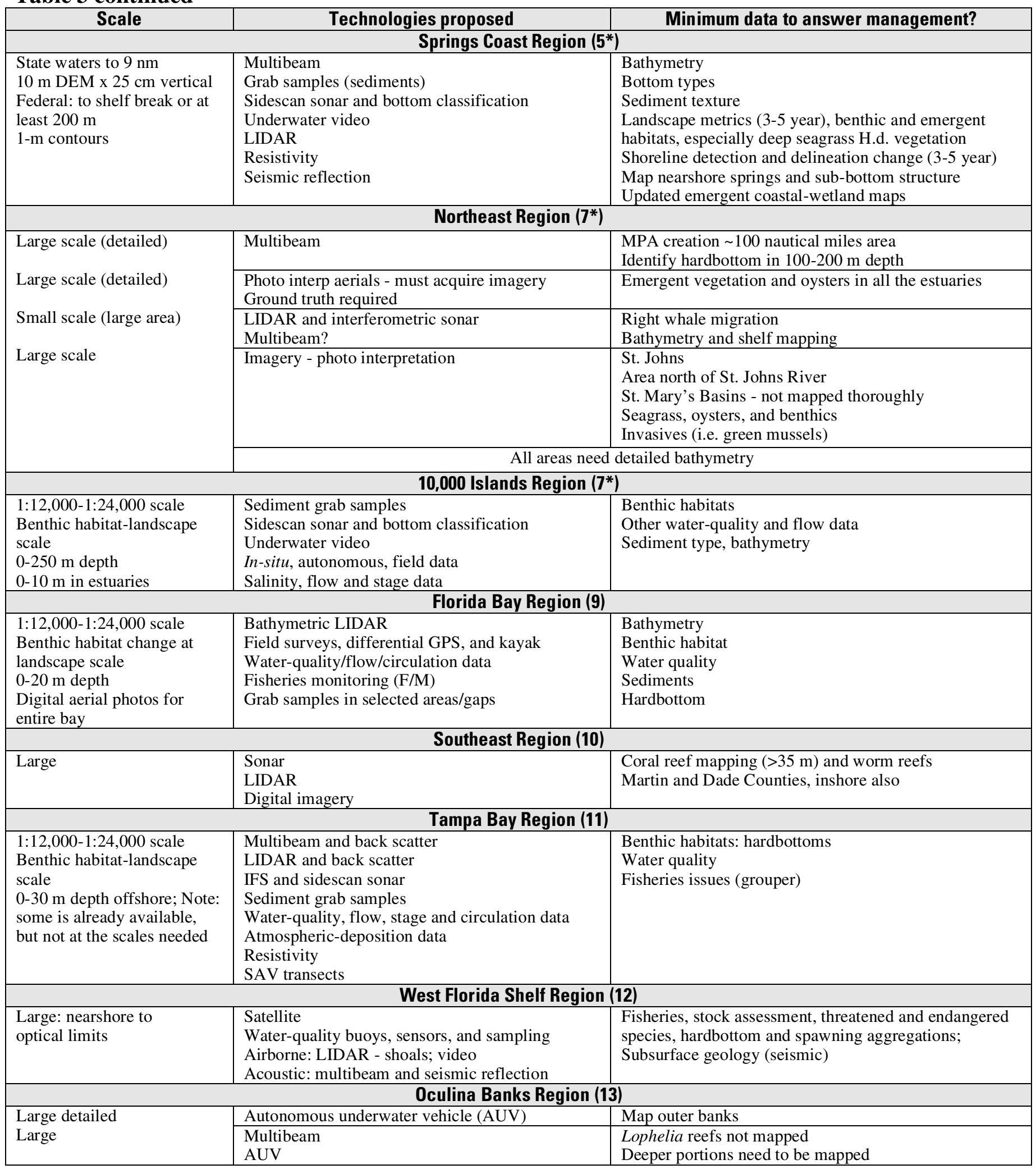




\section{Classification of Habitat and Bioregions}

Classification of habitats over a large region presents difficulties because each technique and each mapping activity has a different capability and purpose. When combining multiple datasets collected by many agencies into a single, comprehensive map, data resolution, spatial correlation, and the different methods of mapping habitats can result in conflicts between habitat designations. Clear matches and data integration may not be possible due to the variety of science and management questions driving each habitat classification effort. An underlying issue behind classification is the designation of bioregions that mesh seamlessly with a regional classification matrix. Workshop sessions were designed to open discussion on existing classification schemes and bioregion distinctions, the potential for a single classification scheme, and the steps necessary to establish classification schemes and bioregion boundaries acceptable to all.

\section{Classification of Habitat}

Several agency efforts have been aimed at developing classification schemes for coastal and marine habitats. NOAA representatives presented the NOAA coral classification scheme and the Coastal and Marine Ecological Classification Standard (CMECS; Madden et al., 2005). The primary compatibility problem identified was the need for finer levels of habitat distinction for corals than CMECS provided. This is a common issue in mapping: regional efforts require gross mapping categories, and local or habitat-specific efforts require a detailed breakdown within the larger categories.

A secondary, but equally important task is the development of a method to blend existing habitat data from different sources into a common habitat-classification scheme. To that end, FWC FWRI developed the System for Classification of Habitats in Estuarine and Marine Environments (SCHEME; Madley et al., 2002). SCHEME was developed specifically to help create maps using multiple datasets by "cross-walking" the data to fix incompatibilities. A cross-walk is a table or matrix that specifies how to link or cluster categories from different sources. Nested or hierarchical classification schemes based on fundamental characteristics such as bottom type, water depth, underlying substrate, vegetation, and water quality can facilitate the resolution of apparent incompatibilities between datasets. Using the same framework, classification schemes can also be blended across the transition to terrestrial habitats. Terrestrial and aquatic system classification schemes have been in use for many years and follow the nested, hierarchical framework (Cowardin et al., 1979; Anderson et al., 1976; Dobson et al., 1995). Other issues discussed include:

1. SCHEME and CMECS II can be nested;

2. standard codes exist all the way down to subclass 4 of CMECS;

3. a seamless transition for land-to-water habitat classification;

4. collaborative effort to guarantee consistent use of modifiers and descriptors;

5. NOAA coral program has not compared their definitions with CMECS but has with SCHEME for those categories that can be cross-walked;

6. NOAA coral program noted that it must maintain compatibility with other coral mapping efforts of the U.S. program. Any standard system used by Florida needs to allow a link between outside projects and projects in Florida;

7. Responses to the question: "Why wouldn't one just use the SCHEME and CMECS systems?"

- NOAA needs to maintain compatibility with existing NOAA Coral Program classification system.

- Categories must be field-tested in a real-life mapping activity prior to inclusion in a classification scheme.

- The amount of detail required is the determining factor. 
8. Is there a central place where descriptors are located now?

- Could use GAME, as SCHEME already does.

At the close of the discussion, NOAA CMECS proposed that they develop a cross tabulation among CMECS, SCHEME, and NOAA schemes. The case was made that as long as the systems can be crossed-walked, then sufficient compatibility would be achieved.

Subsequent to the mapping workshop, an updated version, CMECS III, was to be released at a public workshop in June 2007. This version would be designed to increase compatibility with the major U.S. wetlands classification schemes. A separate SERPPAS workshop is being planned to examine the compatibility further and to seek adoption of a standard habitat-classification system by representatives of the southeastern states. That meeting will help highlight the differences among some existing classification schemes and examine the potential to arrive at a single common habitat-classification scheme for all parties to adopt. Achieving this would allow future habitat-mapping efforts to blend data from different sources more easily.

Three major existing classification systems were presented:

- CMECS, Coastal and Marine Ecological Classification Standard,

- NOAA coral classification scheme,

- SCHEME, System for Classification of Habitats in Estuarine and Marine Environments.

The presentations were followed by a joint question-and-answer session that led to the general conclusion that existing incompatibilities may be resolved, though it would require more time than was available at this workshop. The primary compatibility problem identified among the three systems was that each classification scheme was designed for addressing different map products and management needs from different data sources. The NOAA corals classification scheme was designed to determine zonation, geomorphology, and biological cover from IKONOS satellite data, and was limited to coral reef systems. CMECS II is an ecological classification system that was developed independently of mapping protocols. SCHEME was designed to be altered with "modifiers" to include all habitat types and mapping technologies for ecosystems solely in the Gulf of Mexico.

\section{Designation of Bioregions}

The designation of bioregions, or ecoregions, is typically based on the geographic distribution of biological and physical attributes and the concept of an integrated ecological system. Workshop discussants described four issues around the designation of bioregions: definition, scale, boundaries, and management needs.

\section{Definition}

A bioregion can be defined as, "An area constituting a natural ecological community with characteristic flora, fauna, and environmental conditions and bounded by natural rather than artificial borders" (AHS Dictionary, 2005). The World Wildlife Fund (WWF, 2007) defines an ecoregion as, "A large area of land or water that contains a geographically distinct assemblage of natural communities that

(a) share a large majority of their species and ecological dynamics;

(b) share similar environmental conditions, and;

(c) interact ecologically in ways that are critical for their long-term persistence."

Delineation of a marine bioregion is determined by physical features such as depth and sediment type, biological communities that vary from the surrounding area at a given scale, uniform geologic formations, and chemical similarities (e.g., salinity). 
NOAA has designated the Gulf of Mexico as a single large marine ecosystem (LME; NOAA LME, 2007). At this scale distinctions between regionally important characteristics are lost. The National Estuarine Research Reserve System (NERRS, 2007) delineation of biogeographic regions includes five sub-regions around the State of Florida (Fig. 7a):

Carolinian 7: South Atlantic (Santee River to St. Johns River)

Carolinian 8: East Florida (St. Johns River to Cape Canaveral)

West Indian 9: Caribbean (Cape Canaveral to Ft. Jefferson and south)

West Indian 10: West Florida (Ft. Jefferson to Cedar Key)

Louisianan 11: Panhandle Coast (Cedar Key to Mobile Bay)

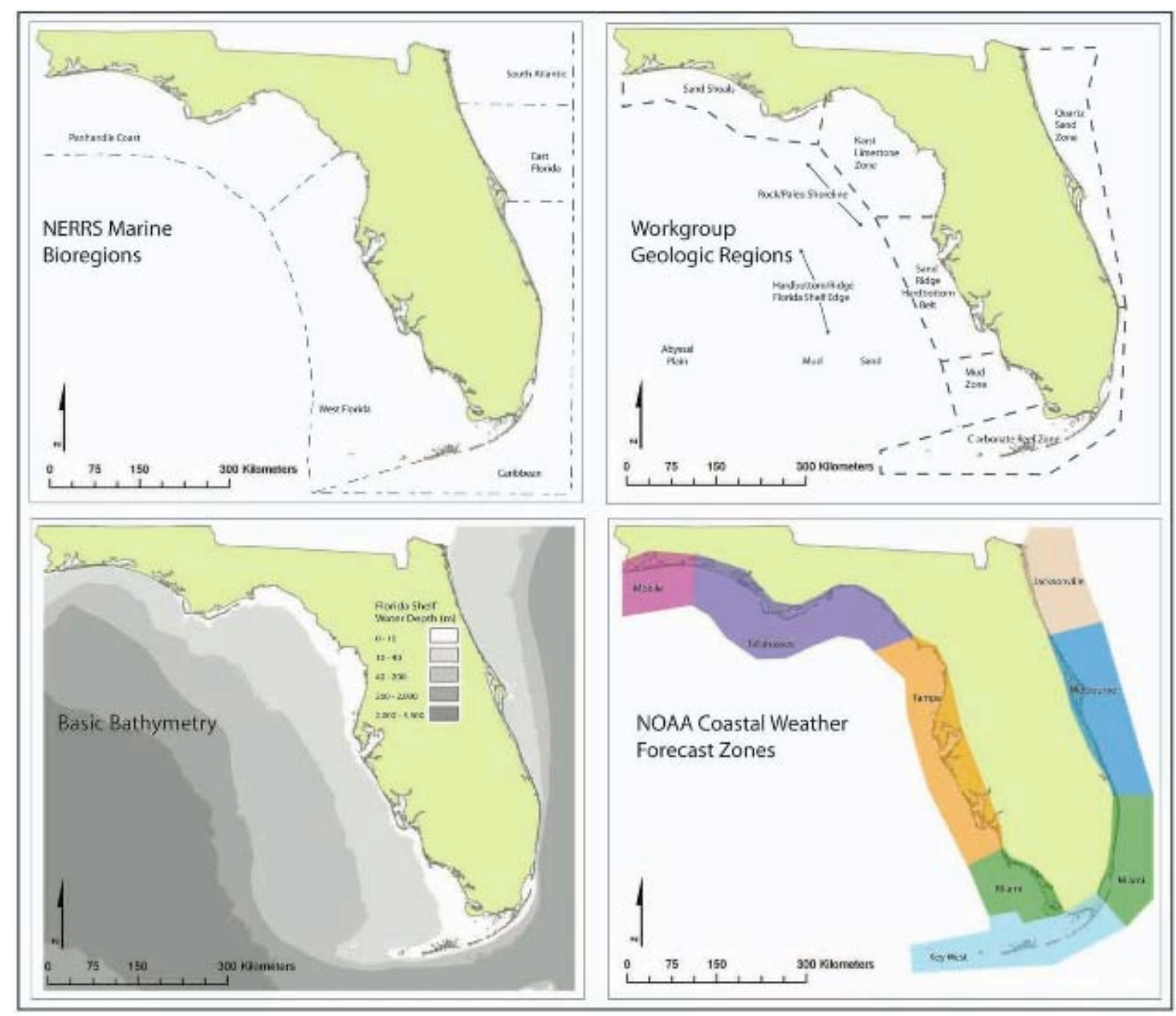

Figure 7. Examples of marine zones: a) NERRS marine bioregions, b) workgroup geologic regions, c) basic bathymetric zones, and d) NOAA weather-forecast zones.

Even the scale of NERRS regions may be too coarse for the type of distinctions needed to manage resources occurring at different depths or in different geologic provinces around the State of Florida. Selection of scale is the first step in designation of marine bioregions of Florida. The bioregion workgroup suggested a minimum mapping unit of $100 \mathrm{~km}^{2}$ for delineation of bioregions. 


\section{Boundaries}

The task of defining useful bioregions also relies on fundamental information on geology, bathymetry, and climate, and the presence or absence of species that serve as keys to habitat function. Thus, the second step toward bioregion delineation is a synthesis of existing data and the demarcation of natural borders based on multiple criteria. The workgroup recommended a combination of:

- geologic provinces;

- bathymetry;

- climate/weather parameters: sea-surface temperature (SST), wind, and salinity patterns;

- ocean-current and gyre patterns and boundaries;

- chemical parameters;

- biological communities.

Discussants provided an initial illustration of Florida marine bioregion boundaries and names based on underlying geology and coastal processes (Fig. 7b). Figure 7c shows basic bathymetric contours. Figure 7d illustrates NOAA coastal-marine weather-reporting zones (NOAA NWS, 2007). Note that the 10 -m bathymetric contour ends and the DeSoto Canyon begins in the western panhandle, approximately where the Mobile/Tallahassee weather zones split.

\section{Management Needs}

A composite map overlay of NERRS marine bioregions, geology, basic bathymetry, and coastal weather zones is shown in Figure 8. The evident boundaries generally concur with the State priority mapping areas shown in Figure 6 but include splits in the NW and NE coastal areas. Not surprisingly, both the management-derived map and the map based on naturally occurring boundaries have much in common.

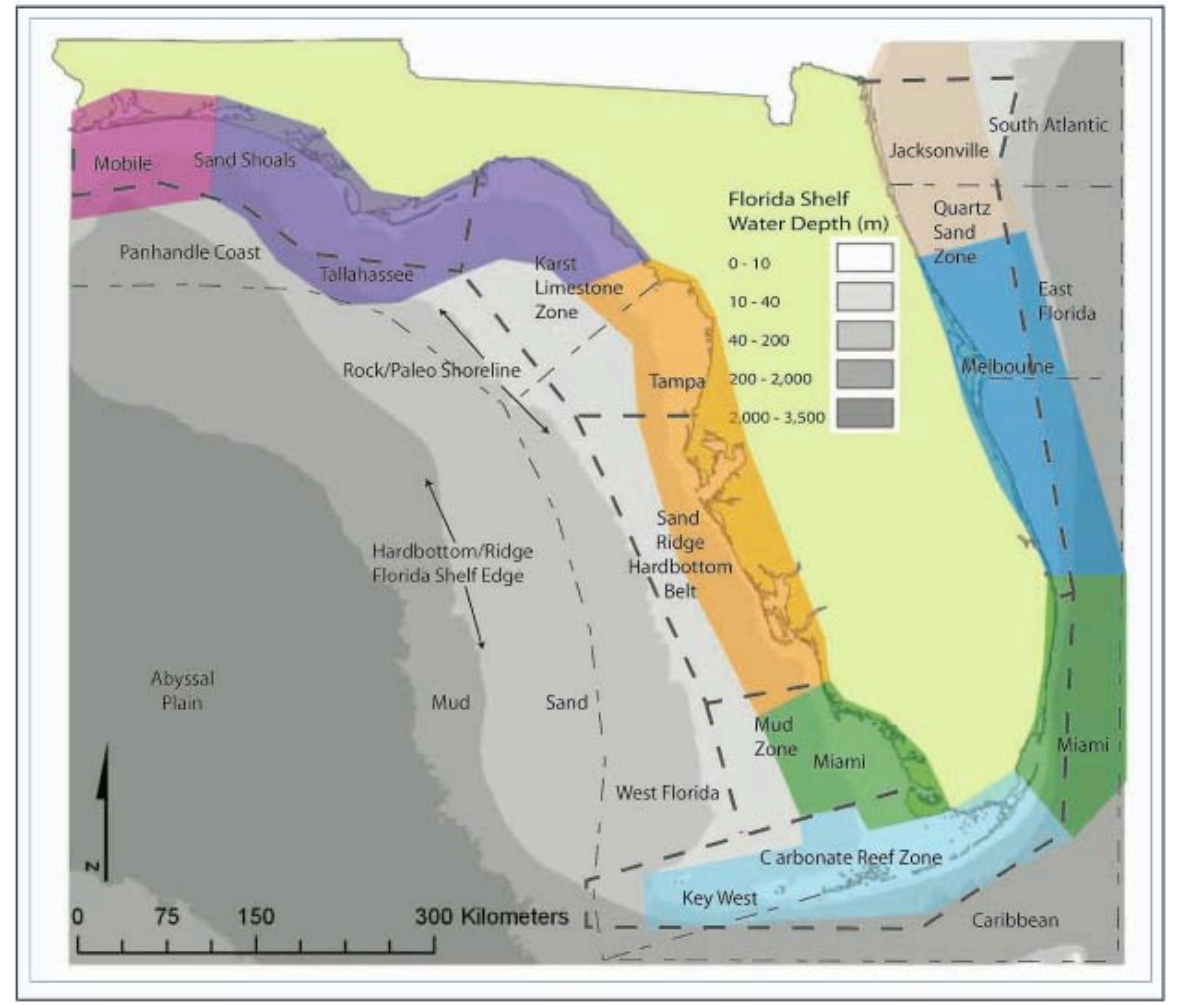

Figure 8. Florida marine-zones composite from NERRS bioregions, geology, bathymetry, and coastal weather zones. 
Boundaries between bioregions are not distinct edges but represent transitional zones, or ecotones, between functionally different areas. The actual line will be somewhat arbitrary since a bioregion is not a physical entity but a conceptual delineation. The workgroup pointed out that designation of a bioregion is a human construct, which can be useful in general assessments, planning, and management. However, bioregions are not static or real entities, and their boundaries may be redrawn according to changing climate, new information, or management needs. For that reason, the selected boundary is less important than the actual work conducted to assess and manage resources in the area.

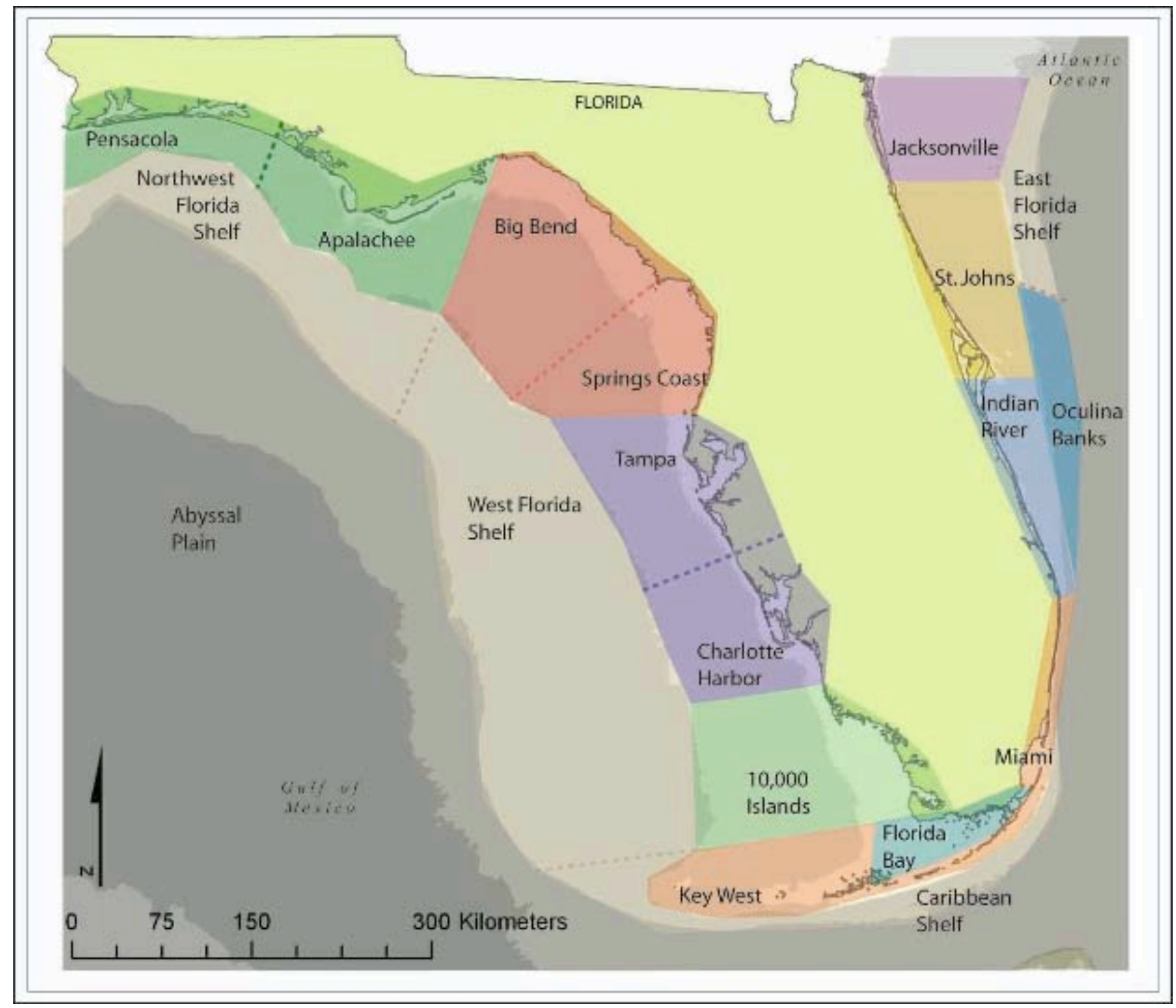

Figure 9. Florida marine bioregions extrapolated from priority mapping areas and natural marine zones.

Figure 9 illustrates a combination of the State priority mapping areas based on management needs (Fig. 6) and preliminary natural boundaries (Fig. 8). The workgroup noted that while there may be sufficient information to initiate demarcation of bioregions, the boundaries could be improved by acquisition and integration of geographically complete baseline data at a100- $\mathrm{km}^{2}$ scale. The workgroup recommended mapping transects across (perpendicular to) suggested bioregion boundaries to verify the location of changes in physical or biological characteristics. It is expected this topic will be pursued as part of a dialogue between management and researchers. 
Additionally, NOAA has developed a Coastal Assessment Framework (CAF) based on watersheds and the interface of watersheds with the marine system (NOAA CAF, 2007). The primary components are: Estuarine Drainage Areas (EDA), Coastal Drainage Areas (CDA), and Fluvial Drainage Areas (FDA). Not surprisingly, most of Florida consists of either EDAs or CDAs. Even this small distinction may be helpful in determining boundary zones near the coast, where freshwater influx originates from significantly different upland or watershed sources.

\section{In-Depth Discussions: Matching Priorities to Next Steps}

\section{Breakout Groups and Plenary Topics}

In-depth discussion groups were formed to address the following topics:

- commonalities among mapping priorities;

- coordination of mapping activities;

- technology;

- designation of bioregions;

- baseline mapping data.

Results of these discussions were combined with existing sections and with feedback on plenary questions. The plenary topics addressed during the workshop were:

- how to make new and existing data available to those who need it;

- how and when to update marine mapping priorities ;

- improved methods for assessing stakeholder priorities;

- advantages and disadvantages to establishing a single Federal mapping priority in Florida.

\section{Coordination of Mapping Activities, Data Availability, and Communication}

There was strong consensus on the need for oversight by a geographic information officer (GIO) or office, a web portal, and requirements for public distribution of data acquired with State or Federal funds. There was also general agreement on the need for future meetings to continue the dialogue and refinement of objective and approach. Existing information and data gaps could be explored individually by agency and stakeholders and presented to the larger group at a future meeting.

Although there is no common 'language' that standardizes how agencies specify their mappingdata needs, the participants felt that there was advantage in creating a glossary of mapping terms, designations for horizontal and vertical resolution, data formats, map standards, data accuracy, and classification schemes that allow integration of datasets between agencies.

\section{Creation of Geographic Information Offic er (GIO)}

A major stumbling block in the reduction of data redundancy and spending inefficiency has been a lack of communication during mapping efforts. Diverse agencies and entities need to be kept informed as each group allocates their limited resources. Most participants felt that projects and their status need to be reported through a mechanism, such as a Coastal Assessment Framework (CAF). There was an enthusiastic agreement that a geographic information officer (GIO) that works closely with FDEP is needed. A board or State geographic planning council could also be created with representatives from all agencies to facilitate information sharing and timely communication. Also, better coordination among Federal, State, academia, and industry will help avoid duplication of efforts and increase output with combined resources.

Along with the GIO, there is an apparent need for a website portal and web-based group forum, although the source of funding for the portal was debated. The web presence and GIO role could start small with one or two people sharing initial responsibilities, information dissemination, and coordination with working groups to link similar mapping needs. This job would ramp up in the long term to build a 
cohesive community, strong communication habits, and a viable office. Some of the functions that the GIO would oversee include:

- website portal, listserve (email and listserver);

- maintaining project-status matrix by soliciting updates on projects;

- developing a list of contacts (include local users such as county planning);

- linking to legislative updates;

- linking to funding sources.

\section{Development of Web Portal One-Stop Clearinghouse of Data}

A majority of participants endorsed an agency or NGO to take ownership of a State-funded or Gulf-wide web portal that would incorporate a GIS database, Internet Mapping Service (IMS), and cataloged data, similar to the Florida GAME program. The State of Florida has several existing web-based mapping efforts: GAME, Land and Boundary Information System (LABINS, 2007), and Florida Geographic Data Library (FGDL, 2007; http://www.fgdl.org/). GAME has been discussed earlier in this report. LABINS and FGDL have been in existence for years, and each serves as a clearing house for raster or vector data, providing data on disk media for a fee. The State Bureau of Beaches and Shores also maintains the Reconnaissance Offshore Sand Search (ROSS, 2007) database for sand resources. Further, it was recommended that any data obtained through State and Federal funds should be entered into a select and common database and that data use should be free of restriction. An annual symposium could be held to introduce data and technologies. Both old and new datasets should be available or should describe metadata such as data source, format, and contact. Other data may be available from numerous sources as provisional data. It was recognized that some data, such as imagery, may be difficult to distribute from a geospatial one-stop due to data storage size and licensing.

Four online State mapping efforts were discussed during the workshop, including FWCC Geospatial Assessment of Marine Ecosystems (GAME, 2008), Reconnaissance Offshore Sand Search database (ROSS, 2007), Florida Geographic Data Library (FGDL, 2007), and Land Boundary Information System (LABINS, 2007). LABINS could be used as a model for successful distribution of imagery by the State at an online portal. Suggested actions are to:

- conduct an inventory of existing portals and select best-fit;

- set up protocols for populating marine database and develop a standardized data format;

- create online matrix of technologies, platforms, and data-product options;

- identify stakeholders beyond State and regional agencies, and open discussion with GIS managers;

- gather a smaller group together to delve deeper into the issues, particularly the priorities identified in this workshop;

- request that vendors contribute specifications such as price, data resolution and accuracy, and turnaround time to make the process competitive.

\section{Updates to Priorities and Stakeholder Input}

State and Federal agency priorities were defined by the individual agencies, based on critical issues, and were prepared in advance, specifically for discussion during this workshop. Agencies described their mapping program and listed the priority issues and areas for mapping. Participants gave substantial comments regarding this workshop and future needs. A majority of participants indicated that workshops, conference calls, emails, and websites were appropriate ways to update or expand on State mapping priorities. It was suggested that the GIO or responsible agency would be tasked with querying agencies for updates to the priority list in the future and making the updates available to the larger community.

The process in this first workshop did not include county and municipal governments, and participants requested more time for discussion and an iterative process with stakeholders. It was suggested that prior to future meetings, agencies should internally evaluate their priority lists by 
conducting local and stakeholder-focused surveys. This step could include focused or local stakeholder meetings, input on missing data, and web or email surveys sponsored by the agency's GIS manager.

Alternatively, the State GIO could develop a list of stakeholders and poll annually via the web. It was suggested that GAME could be modified to incorporate stakeholder input, which would allow for informed prioritization by the agencies. Subsequent interagency coordination and communication will be important. Once priorities are determined by the agencies and submitted to the GIO or responsible agency, the GIO should disseminate updated priority lists and reading material for the participants.

The process of setting priorities, by necessity, must be an iterative process, with stakeholders providing input into State priorities as issues arise. In the event of a new meeting, the GIO would release a preliminary agenda to a broad group, including local planning agencies. Workshops should include discussion of updated priority lists, necessary revisions, progress, and future plans. Participants indicated that the use of interactive maps in workshops would be beneficial, and discussion should be organized by data themes such as bathymetry. It was suggested that a map of existing metadata and mapping efforts be provided to each participant. An overlay of critical issues would help resolve statewide needs and lead to revision of mapping priorities. Another suggestion was to create subgroups to meet on different time frames. Agencies could request conference calls to discuss catastrophic or seminal events and revision of priorities.

Suggestions by the participants for the time frame for updating a priority list ranged widely depending on the particular data needs. An example is a basic bathymetric map could be replaced at 1 to 20 years, depending on local events. Catastrophic events or socio-economic issues could dictate that an area or a habitat be re-mapped over a short time frame, such as 2-5 years, while more static areas could be revisited in 20 or 30 years. A conservative approach would be an annual update of priority mapping locations and topics. An annual review of priorities would facilitate information exchange, mappingactivities updates, and re-allocation of funding among changing priorities. Subgroups may need to meet before budgets and work plans are made. Other participant comments included the need to evaluate management requirements, such as Florida Wildlife Legacy Initiative and Century Commission's Conservation Blueprint, to determine priorities, and a suggestion for a 5-year strategic plan, with annual review to determine progress and re-evaluate priorities.

\section{Funding for Mapping}

Agencies that produce maps and many stakeholders recognized that it would take billions of dollars to map the entire Florida coast and shelf. Since funding has been sparse for mapping initiatives and programs, participants were asked to describe processes that can be used to appropriate or leverage monies for collecting baseline-mapping data (BMD). The following list was compiled:

- legislative process, such as a state legislative budget request (LBR), requires an agency champion;

- local government petitions;

- tie funding to a new, previously unaddressed, "hot" topic;

- tap into existing funding streams (e.g., beach renourishment - Federal, State, local);

- tie into effects or impacts of catastrophic events;

- bonding for data;

- a "penny for..." county initiative;

- revenues generated by licenses, user fees, permits, documentary stamps, or mapping license plates;

- matching-fund grant programs;

- NGO efforts;

- seed monies from State water-management districts;

- "Friends of..." groups, local conservancies, land trusts;

- message that target issues important to program managers and management, not mapping for mapping's sake; 
- soliciting and seeking non-traditional partners: Department of Defense (DOD), Department of Transportation (DOT), agriculture, SERPPAS, industry, utilities/energy (leverage utility corridors), ports, corporate, philanthropic endowments, endowed university programs and institutes (e.g., FGDL, Florida Resources and Environmental Analysis Center [FREAC]).

\section{Formation of Public/Private Partnerships to Support Mapping}

An undertaking as large as mapping the entire Florida shelf will require the combination of many sources of funds. Both private and public sectors often have similar or overlapping objectives, and these interfaces should be investigated. In that light, certain models of public/private partnership to support the mapping effort should be explored, such as The Nature Conservancy model. Within Florida, opportunities present themselves as potential partnerships, including the large tourism and eco-tourism industry (fishing, boating, amusement parks, hotels, recreation industry) and realtors. Another partnership to explore is with Google and Microsoft, in which data are exchanged for products. Corporate stewardship should be explored and encouraged for conservation of resources and wetlands for the Gulf of Mexico region.

Participants recognized that the inclusion of SERPPAS in the workshop opened the door to possible DOD involvement. Priorities for mapping the coast and shelf should be articulated to DOD, with the objective to influence what DOD does in the future. In the future, the private sector should be invited to meetings to be part of the process from planning, to funding, to execution of mapping.

With the large fishing and boating industry in Florida, it is possible to identify "Ships of Opportunity" for some of the data needed. There could be an inventory that lists those types of data that ships, already in operation, could effectively collect. Appropriate sectors within the industry could be approached.

In some states, Minerals Management Service (MMS) has funneled oil- and gas-royalties back to the state. If this could happen in Florida, stipulations should be explored that the monies should be used for baseline mapping of habitats.

- Explore naming rights, such as the "Acme Company" bathymetry dataset.

- Communicate with local government and corporate boards to find areas of common interest, e.g., energy and manatees.

- Lease/purchase to pay for data acquisition.

There are agencies with needs beyond that of the BMD for some portions of the priority area. Suggested alternatives for leveraging/combining funds for the greatest impact/good were:

- piggy-back projects;

- optimize data collection to minimize redundancy;

- share data;

- improve communication in advance of data collection;

- derive additional data products from existing data;

- utilize existing cruise plans or "platform of opportunity."

\section{Advantages and Disadvantages to Establishing a Single Federal Mapping Priority in Florida}

There were many opinions on this topic, split between those in favor of a single overall Federal priority and those in disagreement. Those in favor of a single overall Federal priority suggested that the outcome could be an economy of effort and better employment of resources. If Federal agencies could establish a common goal, then the resources, both financial and logistical, could be allocated to a single goal, allowing for more efficient data coverage, collection, processing, and ultimately a better product. A single overall Federal priority should not take away from ongoing initiatives but should be established with new money. Since funds are limited, there is a need for a collective and integrated support structure behind the fewest number of initiatives possible. Suggested considerations:

- Federal agencies should work with State agencies. 
- State managers want to be sure that Federal agencies do not misunderstand intentions of priority list. Sometimes a small amount of information in many places can be better than a large amount in one place.

- Local entities will still take responsibility for higher-resolution needs that may not be addressed by large area initiatives from Federal agencies.

- A focused effort and continuing long-term support of infrastructure for development, maintenance, and updating of a geo-database could be beneficial.

- Another benefit from a Federal priority is that most State agencies want to map shallow, coastal areas, whereas Federal work can address the deeper, shelf areas.

- The State would still want their institutions, such as FWRI Center for Spatial Analysis, to be an integral part of the effort.

- A focused Federal effort should be supplemented by continuation of a broad effort.

- A Federal effort should be organized by geography and theme with inclusive feedback from stakeholders.

- If there is a Federal priority, it should be general enough to cover the State's needs.

- South Florida Mapping Implementation Plan (MIP) is an example of Federal and State prioritization. Different agencies have different legislative mandates and may require different scales.

- It seems that all State agencies need to set a higher priority on collecting a comprehensive baseline dataset that can be used by all. Federal money and resources can help this effort. State agencies will continue to collect and recollect "pet" areas without concern for other sites and issues; thus, a focused group direction could be critical.

On the other hand, some participants indicated that the Federal agencies need to develop overall regional mapping priorities, not State-specific priorities. Additionally, each agency has its own objectives and mission and the public would be better off if there were better collaboration and communication between agencies. Other opinions expressed during discussion:

- A single-Federal priority should be pursued only if there is a limited amount of funds for a statewide data layer or if Federal agencies have a limited time frame to complete the task or mission.

- Within State waters, Federal efforts should generally defer to the State and support State efforts to coordinate on a regional basis.

- A single Federal priority ought to be State driven.

- The citizens of Florida should establish a single Federal priority.

\section{Baseline Mapping Data}

Baseline mapping data were discussed in a focused breakout group. Major issues for baseline mapping are: consistency in resolution and data type, inclusion of special efforts within routine mapping programs, and discrepancies between budget allocations and real information needs. Another issue is timing of data acquisition for temporal consistency in comparison with future datasets. At a national level, baseline mapping has a terrestrial bias. There is a burgeoning need to establish a foothold for baseline marine maps by lobbying for negative elevation data, integration with topographic data at shorelines, benthic habitat maps, and general content standards for marine mapping efforts.

Baseline mapping data in the marine environment must include bathymetry and seafloor characterization. An ideal baseline dataset includes:

- bathymetry or water depth;

- substrate character with surface sediments;

- geomorphic features such as sand waves;

- $\quad$ subsurface geology (topographic control); 
- living resources such as benthic and sessile species;

- shoreline maps with bathymetric/topographic merge and wetland/upland delineations;

- cultural/archeological features such as wrecks, pipelines, and artificial reefs;

- ground truth - an essential component to achieve mapping accuracy.

The resolution of bathymetry that is already available varies regionally because specifications such as resolution are usually driven by user needs and available technology. However, these variations in data acquisition and product resolution have resulted in inconsistent data quality and data type at the State and National level. Comprehensive data must be merged to the lowest common denominator for common datasets.

Regardless of user specifications, accuracy of maps is a high priority, including both vertical and horizontal spatial accuracy, classification accuracy, and site-specific to regional compatibility. Ground truth, repeatability, and quality assurance/quality control (QA/QC) can be used to assess accuracy.

Mapping efforts must have realistic expectations for the project life cycle and produce sufficient data of the type needed to address management or research questions. Additionally, mapping efforts need to adhere to regulations and statutes and balance data density versus cost. To address data density and cost issues, researchers and State managers need to evaluate methods and study the logistics of mobilization, production rate, site locations, and effective cost sharing.

Data resolution or data density is driven by program need, cost, technology, and time. A regional mapping effort that gives a 'lay of the land' overview will not require as high data density as a detailed site-specific study. However, agencies and research units may benefit from coordination of cost sharing through the determination of commonalities in data needs, despite apparent differences in data density. Temporal variability is also a concern because biomass and geomorphic features may change over time and may need to be addressed by re-visiting the site. Monitoring or change analysis is an important consideration in mapping and one that requires some foresight in the development and archiving of the original datasets.

Based on these discussions, the breakout group recommended that routine mapping efforts be changed to accommodate high-resolution data needs, such as the mapping of anomalous bottom features. Routine mapping programs are usually most cost effective, so changes built into existing programs should not overwhelm either the budget or intent. As an alternative, a secondary program might be initiated to incorporate the increase in data density. Combined baseline mapping efforts should try to maintain flexibility in survey design and operation and use site-specific mapping as "ground truth" where appropriate. All of these suggestions are built on the concept of cost sharing, where the supplemental data collected are funded in part by the agency or research group petitioning for the new data.

In general, the State of Florida needs stronger advocates for marine mapping, for consistency in data acquisition, for statewide coverage, and for distinguishing between budgetary limits and real data needs. To do this, researchers and managers need to establish an ongoing dialogue about issues and imperatives for marine mapping. Additionally, the same issues are faced by marine and coastal management nationwide and warrant participation by Florida in an interstate dialogue.

\section{Workshop Recommendations}

\section{Finding Commonalities among Mapping Priorities}

There are diverse information mapping needs among agencies and these must be assessed through several means. Participants were asked to comment on methods for assessing commonalities among the mapping-data needs and activities of the various agencies. One suggestion was to use an online datamanagement tool like GAME. The current use of this tool allows the collection of standardized information on datasets that are planned, completed, and ongoing. Although there was some concern about negative consequences of including potential future projects, an online tool could be expanded to include updated charts and maps showing upcoming mapping topics or new areas of concern. 
As discussed under State Priority Areas, 13 zones were identified by State agencies as important areas for mapping and were rated according to current level of priority. New mapping efforts will likely focus on the most common mapping needs, although other features may be considered locally. The basic mapping needs most common to all agencies are:

- bathymetry - varying resolution depending on location and depth;

- sea-level rise - need high vertical-resolution bathymetry and topography along coasts;

- shoreline change;

- benthic communities and habitats at appropriate scale;

- subsurface geology;

- $\quad$ sediment types and texture.

Other needs, depending on agency priorities, were suggested:

- human structures - pipelines, cable, artificial reefs, and navigation channels;

- flagship species or charismatic flora, fauna, manatee, threatened and endangered species;

- shorelines and tidal boundaries ;

- overlapping jurisdictions;

- uncommon information - other needs specific to particular agencies;

- Agency-specific needs:

- $\quad$ address issues with conceptual model;

- $\quad$ site-specific needs such as coral, seagrass, navigation channels, or sand resources;

- coordination to reduce incremental cost of added data collection;

- U.S. regional to statewide to individual State regions;

- SE U.S. to Florida to regional planning councils;

- marine boundary working group to GAME to regional planning councils;

- use existing organizations.

Generally, the will and the technology are available for mapping marine habitats, bathymetry, sediment type and thickness, and geology. Coordination of effort, a complete information-gap evaluation, data sharing, and funding coordination are needed. Information sharing between State of Florida agencies, Federal agencies, and the various research entities and service providers involved in marine mapping could be effectively facilitated by establishment of a GIO and stipulations for data format and entry to a common data portal. 


\section{References Cited}

ACT, 2008, Alliance for Coastal Technologies: Interactive query for instruments, sensors, and parameters, http://www.actus.info/tech db.php

AHS Dictionary, the American Heritage® Science Dictionary Copyright @ 2005 by Houghton Mifflin Company. Published by Houghton Mifflin Company. All rights reserved.

Anderson, J.R., Hardy, E.E., Roach, J.T., and Witmer, R.E., 1976, A Land Use and Land Cover Classification System for Use With Remote Sensor Data: U.S. Geological Survey Professional Paper 964, USGS Landcover Institute. http://landcover.usgs.gov/pdf/anderson.pdf

Cowardin, L.M., Carter, V., Golet, F.C., and LaRoe, E.T., 1979, Classification of wetlands and deepwater habitats of the United States. U.S. Department of the Interior, Fish and Wildlife Service, Washington, D.C., Jamestown, ND: Northern Prairie Wildlife Research Center Home Page. http://www.npwrc.usgs.gov/resource/1998/classwet/classwet.htm (Version 04DEC98).

Dobson, J.E., Bright, E.A., Ferguson, R.L., Field, D.W., Wood, L.L., and others, 1995, NOAA Coastal Change Analysis Program (C-CAP): Guidance for Regional Implementation, NOAA Technical Report NMFS 123 - Department of Commerce http://www.csc.noaa.gov/crs/lca/proto2.html

Flocks, J., 2007, High Resolution Seismic Profile presentation, http://www.dep.state.fl.us/marinemapping/workshops/ FDEP, 2007, Florida Regional Marine Mapping Page http://www.dep.state.fl.us/MarineMapping/workshops/

FGDL, 2007, Florida Geographic Data Library, http://www.fgdl.org/

FOCRC, 2007, Florida Oceans and Coastal Resources Council 2006-2007 Annual Science Report http://www.floridaoceanscouncil.org/meetings/files/Research_Plan_FY07-08.pdf

FOCRC, 2008, Florida Oceans and Coastal Resources Council Management Needs '07-'08: http://www.floridaoceanscouncil.org/default.htm

GAME, 2008, Geospatial Assessment of Marine Ecosystems. http://research.myfwc.com/features/category_sub.asp?id=6899

LABINS, 2007, Land Boundary Information System, http://data.labins.org/2003/

Locker, S. 2007, Bottom Acoustics presentation, http://www.dep.state.fl.us/marinemapping/workshops/

Madden, C.J., Grossman, D.H. and Goodin, K.L., 2005, Coastal and Marine Systems of North America: A Framework for a Coastal and Marine Ecological Classification Standard: Version II. NatureServe. Arlington, VA. http://www.natureserve.org/getData/CMECS/metadata intro.htm

Madley, K.A., Sargent, B. and Sargent, F.J., 2002, Development of a System for Classification of Habitats in Estuarine and Marine Environments (SCHEME) for Florida. Unpublished report to the U.S. Environmental Protection Agency, Gulf of Mexico Program (Grant Assistance Agreement MX-97408100). Florida Marine Research Institute, Florida Fish and Wildlife Conservation Commission, St. Petersburg. 43pp.

http://research.myfwc.com/engine/download_redirection_process.asp?file=gomp_report_5955.pdf\&objid=24987\&dltype=article

Nayegandhi, A., 2007, EARRL LIDAR presentation, http://www.dep.state.fl.us/marinemapping/workshops/

NERRS, 2007, National Estuarine Research Reserve System biogeographic regions http://nerrs.noaa.gov/Bioregions/Coverage.html

NOAA CAF, 2007, NOAA Coastal Geospatial Data Project, http://coastalgeospatial.noaa.gov/

NOAA LME, 2007, NOAA Large Marine Ecosystems, http://www.publicaffairs.noaa.gov/worldsummit/lme.html

NOAA NWS, 2007, NOAA Marine Forecast Zones, NOAA National Weather Service Marine Forecasts, Coastal Waters Forecasts by Zone: South and Gulf zones http://www.nws.noaa.gov/om/marine/zone/south/stheastmz.htm

Reich, C., 2007, Streaming Resistivity presentation, http://www.dep.state.fl.us/marinemapping/workshops/

Rohmann, S.O. and Monaco, M.E., 2005, Mapping Southern Florida's Shallow-water Coral Ecosystems: An Implementation Plan. NOAA Technical Memorandum NOS NCCOS 19. NOAA/NOS/NCCOS/CCMA. Silver Spring, MD. 39 pp.

ROSS, 2007, Reconnaissance Offshore Sand Search, FDEP online database; http://ross.urs-tally.com/

USGS, 2008, FISC - St. Petersburg Research and Support Capabilities: U.S. Geological Survey in-house website. http://coastal.er.usgs.gov/capabilities/

WWF, 2007, World Wildlife Fund Ecoregions: http://www.worldwildlife.org/science/ecoregions.cfm 


\title{
Appendix I
}

\section{Workshop Agenda}

\section{Mapping of Florida's Coastal and Marine Resources Setting Priorities WORKSHOP AGENDA \\ Day One: Wednesday, February 7, 2007}

7:30- 8:00 Registration

8:00- 8:30 Welcome and Opening Remarks

8:00-8:20 Welcome by Chairs, SERPPAS Introduction, Workshop Goals

8:20-8:30 Agenda Review and Meeting Guidelines

\section{Presentations: Mapping Technologies, Scales and Resolution}

\author{
8:30-9:15 Bottom and Sub-bottom Acoustics \\ 8:30-8:40 Bottom acoustics - Stan Locker, USF \\ 8:40-8:50 Seismic - Jim Flocks, USGS St. Pete \\ 8:50-9:00 Multibeam - Jane Denny, USGS Woods Hole \\ 9:00-9:15 Question and Answer \\ 9:15-10:00 Remote Sensing (LIDAR, satellite) \\ 9:15- 9:25 CHARTS - Eddie Culpepper, U.S. COE \\ 9:25-9:35 EAARL/ATRIS - Amar Nayegandhi and Dave Zawada, USGS \\ 9:35-9:45 Hyperspectral mapping - Charles Kovach, FL DEP \\ 9:45-9:55 Satellite - Frank Muller-Karger, USF \\ 9:55-10:15 Question and Answer
}

\section{0:15-10:30 BREAK}

10:30-11:00 Autonomous Underwater Vehicles (AUVs) as mapping tools

10:30-10:40 AUV - John Kloske - Center for Ocean Technology, USF

10:40-10:50 AUV - Manhar Dhanak, FAU Seatech

10:50-11:00 Question and Answer

\section{1:00-11:30 New mapping techniques}

11:00-11:10 Hybrid mapping tool \& LIDAR /Single beam - Sam Purkis, NOVA

11:10-11:20 Streaming resistivity - Chris Reich, USGS St. Pete

11:20-11:30 Question and Answer

\section{1:30-12:00 Open Floor discussion on mapping technology}

12:00- 1:30 BOX LUNCH and POSTER SESSION 


\section{Presentation: Identifying Information Gaps}

\section{1:30-1:45 GAME, Geospatial Assessment of Marine Ecosystems}

Florida's first step in an interagency mapping effort - Dave Reed, FWC FWRI

\section{Presentations: Agency Mapping programs, Needs, and Priorities}

$\begin{array}{cc}\text { 1:45-4:10 } & \text { State Agencies } \\ \text { 1:45-1:55 } & \text { Kathleen O'Keife, FWC FWRI } \\ \text { 1:55-2:05 } & \text { Seth Blitch, DEP } \\ \text { 2:05-2:15 } & \text { Ron Hoenstine, DEP FGS } \\ \text { 2:15-2:30 } & \text { Question and Answer } \\ \text { 2:30-2:40 } & \text { Sherman Wilhelm, DACS } \\ \text { 2:40-2:50 } & \text { Graham Lewis, NWFWMD } \\ \text { 2:50-3:00 } & \text { Robert Virnstein, SJRWMWD } \\ \text { 3:00-3:15 } & \text { Question and Answer } \\ \text { 3:15-3:30 } & \text { BREAK } \\ \text { 3:30-3:40 } & \text { Kris Kaufmann, SWFWMD } \\ \text { 3:40-3:50 } & \text { Cecilia Conrad, SFWMD } \\ \text { 3:50-4:00 } & \text { Catherine Corbett, Florida national Estuarine Preserves } \\ \text { 4:00-4:15 } & \text { Question and Answer } \\ \text { 4:15-5:35 } & \text { Federal Agencies } \\ \text { 4:15-4:25 } & \text { Jack Kindinger, USGS } \\ \text { 4:25-4:35 } & \text { Steve Rohmann, NOAA } \\ \text { 4:35-4:45 } & \text { Jennifer Moore, NOAA- NMFS } \\ \text { 4:45-5:00 } & \text { Question and Answer } \\ \text { 5:15-5:25 } & \text { Matt Patterson, National Park Service (NPS) } \\ \text { 5:25-5:35 } & \text { Mary Bryant, TNC } \\ \text { 5:45-6:00 } & \text { Question and Answer } \\ \mathbf{6 : 0 0} & \text { Adjourn } \\ & \end{array}$




\section{Mapping of Florida's Coastal and Marine Resources Setting Priorities \\ WORKSHOP AGENDA \\ Day Two: Thursday, February 8, 2007}

7:30- 8:00 Registration

8:00-8:15 Good Morning, Agenda Review and Goals for the Day

Mapping priorities and coordination of efforts

8:15-8:45 Commonalities of Priorities - Overview and Discussion

8:45-10:45 Breakout Sessions (Includes break)

Group One: Discussions of Coordination, Commonalities and other issues

Group Two: Identification of State of Florida Priorities for SERPPAS

Participation by Florida agency-designated representatives

10:45-12:00 Group Reports with Plenary Discussion

12:00-12:30 State Priority Results with Plenary Discussion

12:30-1:30 BOX LUNCH and POSTER SESSION

1:30-2:45 Classifying Habitats for Mapping

1:30-2:15 Presentations:

Becky Allee, NOAA CMECS

Steve Rohman, NOAA NOAA coral scheme

Katherine O'Kiefe, FWC FWRI SCHEME

2:15-2:45 Open Discussion

In-Depth Discussion: Matching Priorities to Next-Steps

2:45-3:15 Plenary Questions

3:15-5:00 Breakout Groups - Questionnaire and Next Steps of Priorities

5:00-5:15 Closing Remarks

5:15-5:30 Evaluations

5:30 Adjourn 


\section{Appendix II}

\section{Organizers}

Name

Camille DeStafney

Lisa Robbins

Steven Wolfe
Affiliation

U.S. Navy; SERPPAS

U.S. Geological Survey

Florida DEP
Email

camille.r.destafney@navy.mil

1robbins@usgs.gov

$\underline{\text { Steven.Wolfe@dep.state.fl.us }}$

\section{Workshop Participants}

Becky Allee, NOAA

Will Allen, The Conservation Fund

Seth Blitch, FDEP CAMA

Bill Braunsch, SWFWMD

Scott Brewer, USMC, SERPPAS

Mary Bryant, TNC

Paul Buchanan, SRWMD

Paul Carlson FWC FWRI

Libby Carnahan, FDEP CAMA

Cristina Carollo FIO, FWC FWRI

Cecilia Conrad, SFWMD

Gary Cook - FDEP BCS

Eddie Culpepper, USACE

David Dale, NMF-NOAA

Braxton Davis, South Carolina SERPAS, SERPPAS

Jane Denny, USGS

Calvin DeSousa - FDOH

Camille Destafny - Navy

Manhar Dhanak - FAU Seatech

Shane Dunn, USF Marine Science

Brock Durig, Navy, SERPPAS

Fred Engle, Office of the Secretary of Defense, SERPPAS

Virginia Fay, NOAA

Mark Finkbinder, NOAA

Jim Flocks, USGS

Greg Foster, Nova SE

Sandra Fox, SJRWMD

Paul Friday, USMC, SERPPAS

Chris Friel, Photo Science

Lauren Hall, SJRWMD

Jack Hampson, PBSJ

Stacey Harter, NOAA Fisheries

Al Hine, USF

Ron Hoenstine, FDEP FGS

Kristin Kaufman, SWFWMD

Brian Keller, NOAA

Jack Kindinger, USGS

John Kloske, USF COT

Kevin Kohler, Nova SE

Stephen Kopach, MMS

Charles Kovach, FDEP

Craig Kreumpel, Coastal Planning \& Eng., Inc.

Graham Lewis, NWFWMD

Jeff Lillycrop, USACE

Stan Locker, USF

Matt Love, FDEP CAMA

Mark Luther, USF

Mark Monaco, NOAA

Frank Muller-Karger, USF

Dave Naar, USF

Amar Nayegandhi, USGS

Harry Norris, FWC FWRI

Kathleen O'Keife, FWC FWRI

Dave Palandro, FWC FWRI

Matt Patterson, NPS

Keith Patterson, Avineon

Simon Pittman, NOAA

Roger Pugliese, South Atlantic Fish Management Council

Sam Purkis, Nova SE

Ellen Raabe, USGS

Samual Rajasekhar, SJRWMD

Dave Reed, FWC FWRI

Chris Reich, USGS

Marta Ribera, NOAA Fisheries

Bernhard Riegl, Nova SE

Lisa Robbins, USGS

Steve Rohmann, NOAA

Barry Rosen, USGS

Peter Rubec, FWC FWRI

Chris Russo, North Carolina, SERPPAS

Mike Street, NC DMF, SERPPAS

Beau Suthard, Coastal Planning \& Eng., Inc

Jim Tilmant, NPS

Robert Virnstein, SJRWMD

Thomas Watters, FDEP BCS

Sherman Welhelm, DACS

Jerry Wilson, Fugro Pelagos

Steve Wolfe, FDEP CAMA, SERPPAS

Spud Woodward, Georgia, SERPPAS

Wayne Wright, NASA

Linda York, NPS

Dave Zawada, USGS 


\section{Participating Agencies and Institutions}

Avineon, Inc.

Center for Ocean Technology at USF (COT)

Coastal Planning and Engineering, Inc. (CPE)

Department of Defense (DOD)

Florida Atlantic University (FAU)

Florida Beaches and Coastal Systems (BCS)

Florida Coastal and Aquatic Managed Areas (CAMA)

Florida Department of Agriculture and Consumer Services (DACS)

Florida Department of Environmental Protection (FDEP)

Florida Department of Health (FDOH)

Florida Fish and Wildlife Conservation Commission (FWC)

Florida Geological Survey (FGS)

Florida Institute of Oceanography (FIO)

Florida International University (FIU)

Florida Wildlife Research Institute (FWRI)

Fugro Pelagos, Inc.

Minerals Management Service (MMS)

National Aeronautics and Space Administration (NASA)

National Marine Fisheries Service (NMFS)

National Oceanic and Atmospheric Administration (NOAA)

National Parks Service (NPS)

North Carolina Division of Marine Fisheries (NC DMF)

Northwest Water Management District (NWRMD)

NOVA Southeastern University

Photo Science

Post, Buckley, Shuh, and Jernigan, Inc. (PBSJ)

Sea Tech, Inc.

South Atlantic Fish Management Council (SAFMC)

South Florida Water Management District (SFWMD)

Southeastern Partnership for Planning and Sustainability (SERPPAS)

Southwest Florida Water Management District (SWFWMD)

St. Johns Water Management District (SJWMD)

Suwannee River Water Management District (SRWMD)

The Conservation Fund

The Nature Conservancy (TNC)

U.S. Army Corps of Engineers (USACE)

U.S. Geological Survey (USGS)

U.S. Marine Corps (USMC)

U.S. Navy

University of South Florida (USF) 